\title{
Farmacovigilância: elementos para a discussão e perspectivas
}

\author{
Drug surveillance: topics for discussion \\ and prospects
}

Suel y Rozenfel d 1

\footnotetext{
1 Escola Nacional de Saúde Pública, Fundação Oswaldo Cruz.

Rua Leopoldo Bulhões 1480, 8 andar, Rio deJaneiro, RJ 21041-900, Brasil.

rozenfeld@ensp. fiocruz.br
}

\begin{abstract}
Drug surveillance can be grouped into two areas. The first includes registration and inspection, activities that are more familiar to society at large. The second involves research and monitoring of adverse effects. Brazilian legislation has regulated this subject since 1970. A recent directive also provides for a national pharmaceutical surveillance system. This current article provides an overview of the history, definitions, pharmacological concepts, classification, and diagnosis of the adverse effects of drugs. An analysis is presented of the goals and sources of information for drug monitoring as well as some Brazilian experience in this field.

Key words Pharmacology; Drug Surveillance;Drugs; Secondary Effects

Resumo A vi gilância de medicamentos subdivide-se em dois grupos. O primeiro consiste nas ações de registro e fi scal ização, que são as mais conhecidas da soci edade. O segundo grupo consiste nas ações de farmacovi gil ância, que são as de pesquisa e monitoramento de reações adversas. Essas últimas estão previstas na legi sl ação federal do setor saúde que vigora desde a década de 70. Do mesmo modo, uma portaria recente prevêa criação do sistema nacional de monitoramento. O texto aborda de manei ra panorâmica el ementos da história, dos conceitos, das definições, da classi ficação, dos mecanismos de ação e do diagnóstico de reações adversas. São descritos os objetivose as fontes de informação para os estudos de farmacovigi lância, bem como a experiência nacional no campo.

Palavras-chave Farmacologia; Farmacovigilância; Medicamentos; Efeitos Secundários
\end{abstract}


Introdução

As atividades governamentais destinadas a garantir a qualidade dos medicamentos e a assegurar o seu uso seguro e eficaz são conhecidas internacionalmente como Drug Regulation e no Brasil como Vigilância Sanitária de Medicamentos.

O termo vigilância (surveillance) é empregado em saúde pública há cerca de um século para o acompanhamento dos contatos de casos de doenças transmissíveis sem o isolamento dos pacientes, e ao diagnóstico precoce. A partir da década de 50 adquiriu um sentido mais abrangente, significando o acompanhamento sistemático de doenças ou de eventos adversos na comunidade (Wal dman, 1991).

Embora o registro e a fiscalização de medicamentos em nosso país existam desde a época do Brasil Colônia, o campo estruturou-se na década de 70. Criou-se, no âmbito do Ministério da Saúde (MS) o que passou a ser conhecido como Vigilância Sanitária, tal vez pela tendência neste período de empregar vigilância como acompanhamento de malformações congênitas, envenenamentos na infância, leucemia, abortos, acidentes, doenças profissionais, problemas ambientais e resultantes da utilização de tecnologias médicas, entre elas os medicamentos (Wal dman, 1991).

Várias leis e decretos sacramentaram a criação da 'vel ha-nova' área, entre eles as Leis no 6.229 de 1975, no 6.360 de 1976 e no 5.991 de 1973, e os Decretos no 79.094 de 1977 e no 79.056 de 1976 (MS, 1978). As atividades dispersas foram sistematizadas e estabel eceu-se um corpo normativo e institucional responsável por: el aborar normas, executar inspeções, conceder registros e certificados, divulgar as decisões regulatórias, identificar fraudadores e aplicar penalidades. A legislação vigora até hoje e atinge os processos de prescrição, produção, transporte, distribuição, importação e exportação de medicamentos. Tais ações são privativas da autoridade sanitária dotada de poder de polícia e incidem sobre o agente potencialmente causador do dano, vale dizer, cada um dos elementos da cadeia de produção.

Mas a legislação prevêtambém a atuação da vigilância sobre os usuários dos produtos. Diz o artigo 79 da Lei 6.360 de 1976 que "todos os informes sobre aci dentes ou reações nocivas causadas por medicamentos serão transmiti dos à autoridade sanitária competente". Portanto, subentende-se que a notificação de reações adversas para um Sistema Nacional de Farmacovigilância é obrigatória. Farmacovigilância é o conjunto de métodos e técnicas que têm por objetivo a identificação e a aval iação dos efeitos do uso, agudo ou crônico, do tratamento farmacológico no conjunto da população ou em subgrupos de pacientes expostos a tratamentos específicos (Tognoni \& Laporte, 1989). Diferentemente do registro e da fiscalização - atos privativos das autoridades sanitárias com poder de polícia - o monitoramento de reações adversas pode ser executado nas universidades, nos institutos de pesquisa ou na rede de assistência à saúde. Não obstante o enorme leque de possibilidades institucionais, a notificação ainda é incipiente no País e inexiste o sistema nacional.

Há indícios, entretanto, de que o panorama está se transformando. A Secretaria Nacional de Vigilância Sanitária, através da Portaria SVS no 40 de 09/05/95, criou uma comissão para propor a implantação de um Sistema Nacional de Farmacovigilância (Arrais, 1995). Em razão disso, é oportuno revisar os aspectos básicos ligados ao elemento central da farmacovigilância, a saber, as reações adversas. Ao final, será oferecida uma visão das condições atuais do campo em nosso meio.

\section{Definições e conceitos}

O estudo dos efeitos adversos causados pelas substâncias químicas nos organismos vivos éa Toxicologia. A Farmacologia Clínica éa disciplina que trata dos benefícios e dos danos potenciais dos fármacos nos seres humanos (Goodman \& Gilman's, 1996). Segundo a Organização Mundial da Saúde (OMS) fármaco é qualquer substância ou produto usado ou que se pretende usar para modificar ou explorar sistemas fisiológicos ou estados patológicos em benefício de quem o recebe (WHO, 1972).

O tratamento adequado ao tema requer a apresentação da terminologia oficial no Brasil (MS, 1978). Segundo a Lei no 5.991/ 73, droga é uma substância ou matéria-prima com finalidade medicamentosa ou sanitária; medicamento é um produto farmacêutico, tecnicamente obtido ou elaborado, com finalidade profilática, curativa, paliativa ou para fins de diagnóstico; insumo farmacêutico é uma droga ou matéria-prima aditiva ou complementar de qualquer natureza, destinada a emprego em medicamentos, quando for o caso, e seus recipientes. Apesar das definições legais, não é recomendável empregar a palavra droga para se referir à matéria-prima, dada a sua evidente associação com as drogas ilícitas, preferindose fármaco, substância ativa ou princípio ativo. O termo especialidade farmacêutica é sinônimo de produto medicamentoso. 
Em meados da década de 60, consideravase reação adversa ou efeito indesejável como sendo a piora do estado clínico ou biológico de um indivíduo, que o médico atribuía à tomada de um medicamento em doses habitualmente utilizadas e que demandava uma terapêutica, a diminuição da dose ou ainda a suspensão do tratamento, senão geraria um risco incomum no caso de tratamento posterior com o mesmo medicamento (Dangoumau et al., 1978). Tratase de uma definição que tem a marca da sua época: ênfase nos aspectos biológicos e no diagnóstico atribuído ao médico. Posteriormente, a OMS definiu reação adversa como sendo aquela que é nociva, involuntária e que ocorre nas doses normal mente usadas em seres humanos (WHO, 1972). A maioria delas é leve e não requer o uso de antídotos; um número menor é de gravidade moderada, podendo causar ou prolongar a internação hospitalar ou demandar o uso de antídotos; num número ainda menor, a reação é grave, pois ameaça a vida ou leva à morte.

Há várias expressões usadas para caracterizar os eventos adversos. As palavras acidentes e intoxicações sugerem inadequações na produção, na circulação ou no uso de produtos farmacêuticos. Nestes casos, é costume atribuí-los a medicamentos fraudados, contaminados, adulterados ou falsificados. Tais expressões são empregadas na própria legislação brasileira sugerindo intencionalidade dos produtores, dos distribuidores, dos provedores de atenção à saúde ou dos usuários, tais como, ingestão de doses anormais com finalidade não terapêutica; prescrição ou dispensação quando há restrições de uso ou contra-indicações; adulteração na fabricação, na comercialização ou no transporte dos produtos por motivações comerciais. Conforme consta no artigo 48 da Lei no 5.991/ 1973 (MS, 1978), uma vez “comprovada a al teração, fal sificação, adulteração ou fraude, será lavrado, de imediato, auto deinfração e notificada a empresa para início do processo". A palavra "acidente' usada nestes casos seria, portanto, inadequada, uma vez que atribui aos eventos o caráter aleatório.

Os termos reações ou efeitos adversos, colaterais ou indesejáveis focalizam os resultados da utilização dos produtos e relacionam-se às suas características intrínsecas e à prescrição. Às vezes, emprega-se a palavra iatrogenia, que significa qualquer malefício ocasionado pelos procedimentos médicos. Tais termos sugerem o emprego de medicamentos em circunstâncias nas quais o conhecimento clínico-farmacológico é insuficiente para evitar o dano, dado o estágio atual das pesquisas no plano interna- cional; ou ainda, nos casos em que a análise benefício/ risco é favorável, em que os benefícios superam os riscos.

O controle dos problemas daí decorrentes envolve mecanismos de defesa criados pela sociedade para salvaguardá-la dos danos potenciais dos medicamentos, mecanismos estes que podem ser agrupados sob o rótulo de 'estratégias para o uso racional'. Com relação aos 'acidentes' e 'intoxicações', o controle é feito por meio da aplicação rigorosa da lei, identificando as irregularidades e punin do os infratores. As autoridades sanitárias responsáveis atuam nas vigilâncias sanitárias municipal, estadual ou federal (Rozenfeld, 1989) e nos Conselhos de Classe. Embora as reações adversas aos medicamentos sejam definidas pela OMS como evento involuntário, não há como desconsiderar a sua ocorrência por imperícia, imprudência ou negligência.

\section{Reações adversas - alguns marcos históricos}

A história da identificação das reações adversas está articulada à da criação pelo Estado de normas para garantir a qualidade dos remédios e proteger a saúde da população contra o charlatanismo e a fraude. Isso ocorreu ao longo dos tempos tendo como pano de fundo as mudanças sociais, o avanço das ciências básicas e, particularmente, a atuação da saúde pública através dos seus órgãos de controle e de regulamentação. Tais órgãos estão hoje implantados na maioria dos países. Há também instituições internacionais participando deste esforço, tais como, a OMS, a Organização das Nações Unidas (ONU) e a Comunidade Econômica Européia.

Tempos Antigos - O registro das reações adversas e o das punições aos responsáveis é tão antigo quanto a história do homem e da medicina. O Código de Hammurabi da Babilônia, datado de 2200 aC, dizia que um médico que causasse a morte de um paciente perderia as mãos. Hipócrates (460-570 aC) preconizava “Não cau sem dano", e Galeno (131-201 dC) advertia contra os perigos das prescrições mal escritas e obscuras. Os efeitos tóxicos do arsênico e dos ungüentos de mercúrio eram conhecidos. Em 1224 o Imperador de Hohenstaufen, Frederico II, implantou a inspeção regular dos compostos preparados nas farmácias e declarou que a vida de um fornecedor seria sacrificada caso o consumidor morresse. No Renascimento (1500-1750) surgiram as farmacopéias. Os autores da primeira Farmacopéia de Lon- 
dres, em 1618, condenavam as pessoas que vendiam as mais repugnantes misturas sob a designação de remédio, embora eles mesmos incluíssem vermes, serpentes secas e pulmão de raposa no catálogo de medicamentos aceitáveis (Davies, 1987).

No século XVII, pela primeira vez, uma droga foi proscrita por causa da sua toxicidade. Os membros da Faculdade de Medicina de Paris foram proibidos de usar antimônio, mas o banimento não foi mantido, pois atribuiu-se ao antimônio a cura de um ataque de febre tifóide sofrido por Luís XIV. Escritores famosos pontificavam sobre o assunto; Voltaire dizia que os médicos "entornavam drogas que pouco conheciam em corpos que con heciam menosainda". Uma epidemia de febre amarela em alguns estados norte-americanos conferiu notoriedade ao mercúrio; os médicos acreditavam que a cura da doença estava na expulsão de substâncias biliares fermentadas no trato gastrintestinal e por isso recomendavam-no em altas doses misturado com outros purgantes. Alguns pacientes apresentaram perda dos dentes, úlcera ou gangrena da boca e face e osteomielite da mandíbula. Ainda assim, ele continuou sendo usado pelos médicos por muitos anos (Davies, 1987).

No Brasil, as ordenações do Reino do século XVI estabeleceram que a distribuição de drogas era privativa de boticários. Em 1744 o regimento do físico-mor do Reino proibiu a distribuição de drogas por estabelecimentos não habilitados, fixando multas e apreenden do estoques nos casos de violação da lei; criou a figura do profissional responsável; exigiu que as boticas possuíssem balanças, pesos, medidas, medicamentos galênicos, produtos químicos, vasilhames e livros elementares e criou a fiscalização sobre a conservação das drogas e dos vegetais medicinais (Zubioli, 1992).

Entre 1750 e 1830, na Europa, surgiram os primeiros registros nacionais de mortalidade e os inquéritos regionais. Acirrou-se a competição entre os produtores, gerando a necessidade de regulamentação para evitar a concorrência fraudulenta. No campo da administração, Johann Peter Frank e Franz Anton Mai assentaram as bases da polícia médica exercida pelo Estado, marco inaugural da medicina social (Rosen,1994) e ancestral direto da vigilância sanitária.

No início do século XIX, dois acontecimentos marcaram o desenvolvimento industrial farmacêutico e a regulamentação dos medicamentos: a lei de patentes e o isolamento da morfina pura a partir do ópio em 1805 (Lee \& Herzstein, 1986). Surgiram novas farmacopéias em vários países e pela primeira vez estabele- ceram-se os padrões de pureza dos fármacos. Em 1848 foi criado o primeiro estatuto de controle da qualidade dos fármacos nos Estados Unidos após o episódio de importação para o Exército de quinina adulterada (Davies, 1987).

Enquanto isso, no Brasil, criou-se em 1809 no Rio de Janeiro a cadeira de Medicina Clínica teórica que continha matéria médica e farmacêutica, polícia médica, higiene e terapêutica. As visitas às boticas e as inspeções sanitárias eram exercidas pelo físico-mor e cirurgião-mor do Império até 1828 , e posteriormente pelas Câmaras Municipais. Mais tarde, a Sociedade de Medicina passou a exercer algumas ações de regulamentação, tais como aplicar multas aos que faziam propaganda em lugares públicos, anunciavam a cura pela imprensa ou vendiam remédios não aprovados pela Sociedade ou por uma faculdade de Medicina (Machado et al., 1978).

Nos últimos anos do século XIX e no início do século $X X$, apareceram na Inglaterra, na Suíça e nos Estados Unidos as primeiras legislações e órgãos específicos de controle de medicamentos, com ênfase na proteção do consumidor contra as fraudes. Mas a Noruega e a Suécia foram pioneiras no desenvolvimento de uma regulamentação voltada não somente para a segurança, mas também para a eficácia dos fármacos (Lee \& Herzstein, 1986). Neste período ocorreram importantes inquéritos sobre suspeitas de reações adversas, tais como os referentes às mortes súbitas durante anestesia por clorofórmio e à icterícia após o uso de arsenicais no tratamento da sífilis. Assim, a American Medical Association criou o Council on Pharmacy and Chemistry, e finalmente surgiu o American Food, Drug and Inseticide Administration, que mais tarde originou a agência norte-americana de regulamentação, o Food and DrugAdministration/FDA (Davies, 1987).

O surgimento de um dos órgãos de controle mais influentes no mundo não impediu a ocorrência, em 1937, de mais de cem mortes pelo dietilenoglicol contido no xarope de sulfanilamida, cujos efeitos tóxicos já estavam documentados. No rastro deste desastre, o Congresso norte-americano aprovou o Food, Drug and Cosmetic Act, alterando a regulamentação dos medicamentos e influenciando outros países. A nova legislação proibiu a comercialização de novos fármacos sem a autorização do FDA, concedida mediante comprovação de sua segurança pelo fabricante. Deixava-se a cargo do médico a avaliação da eficácia (Lee \& Herzstein,1986).

No Brasil, entre a segunda metade de século XIX e a primeira metade do século XX, apa- 
receram as primeiras regulamentações para garantir a qualidade dos medicamentos. Elas são contemporâneas de denúncias como a que se segue, publicada em 1918 por Monteiro Lobato: “Em matéria de drogas nem é bom falar. I odofórmio adulterado com enxôfre. Emetina fabricada com sais de quina. Quinino easpirina feitos com lactose. Óleos minerais e medicinais clarificados com ácido sulfúrico impuríssimo, contendo arsênico. E, cúmulo, 914 em ampolas que não passa definíssimo fubá demilho amarelo... São Paulo virou o paraíso da fraude bromatológica. Indefesa como está a cidade, confiada a uns fi scais que fiscalizam para sí, os desalmados envenenam-nos por todas as viase amontoam fortunas colossais à custa da saúde alhei a... São duas coi sas que, arre! valem a pena: falsificar e fiscal izar" (Lobato, 1964).

No plano federal, o Decreto no 19.606/ 1931 estabeleceu as normas para o controle sanitário e a atuação da indústria farmacêutica no Brasil, inovando em alguns aspectos, entre os quais o condicionamento da venda dos produtos que agem sobre o sistema nervoso central e causam dependência física ou psíquica à retenção da receita médica na farmácia (Zubioli, 1992). Em 1934, o Relatório da Inspetoria de Farmácias menciona o fechamento de um laboratório devido à denúncia de “intoxicação de um cidadão por apli cação ao mesmo de duas ampolas de auto-vacina estafi locócica do laboratório em questão que após procedi das todas as formalidades legais foi multado e fechado, pois também tinha o agravante de não possui $r$ licença da Diretoria Geral de Sáude" (Guedes, 1990).

No plano regional, os Estados do Paraná e de São Paulo foram pioneiros. No Paraná, a legislação de 1864 regulamentou a concessão de habilitação para o exercício da medicina e da farmácia (Guedes, 1990). Em São Paulo, criouse no final do século XIX um corpo de delegados para fiscalizar as profissões médicas, e em 1938 o Serviço de Laboratórios de Saúde Pública, abrangendo o Instituto Butantã, o Instituto Bacteriológico e o Laboratório de Análises Químicas e Bromatológicas; os dois últimos fundiram-se dois anos depois para dar origem ao Instituto Adolfo Lutz, órgão de referência para o controle de qualidade até os dias atuais (Waldman, 1991).

Apesar da criação dos órgãos de controle e da di vulgação dos graves acidentes relacionados ao uso dos medicamentos no Brasil e no mundo, a difusão de informações sobre toxicidade sempre foi tardia e muitas vezes de efeito transitório. Assim é que foram necessários 47 anos para se descobrir que o analgésico ami- dopirina produzia intoxicação medular; a aspirina foi usada durante 39 anos antes de ser incriminada como responsável por causar hemorragia gástrica e outros vinte para que a notícia se espalhasse; os perigos do cloranfenicol foram observados no início da década de 50 , mas décadas depois as advertências ainda eram desconsideradas (Davies,1987).

Graças ao acúmulo de conhecimento no campo das ciências biomédicas e à concentração de recursos financeiros engendrada no Pós-Guerra, testemunhou-se, entre as décadas de 30 e 60, o mais intenso desenvolvimento de toda a história das descobertas de agentes profiláticos e terapêuticos. Surgiram os antibióticose os tranqüilizantes que revolucionaram a própria prática médica. Paralelamente, aparece em 1952 o primeiro livro inteiramente dedicado às reações adversas e, no mesmo ano, o Council on Pharmacy and Chemistry da American Medical Association implanta uma organização para monitorar as discrasias sangüíneas induzidas por fármacos (Davies, 1987).

Tempos Modernos - Em 1961, surgiram as primeiras notícias dos efeitos danosos da talidomida - o nascimento de bebês com deformidades dos membros. O episódio marcou tragicamente o início de uma nova era no controle das reações adversas aos fármacos, caracterizada pelo lançamento de estratégi as mais inteligentes e menos policiais e pel a diversificação e expansão dos mecanismos de regulamentação e monitoramento. Multiplicaram-se as iniciativas em todos os níveis da organização social: nacional, supranacional e regional. Muitos países criaram agências para tratar da segurança no uso dos fármacos e praticamente todos os países europeus desenvolveram regulamentos específicos (Lee \& Herzstein, 1986).

Os EUA aprovaram, em 1962, a emenda Kefauver-Harris, reforçando os requisitos do FDA para comprovar a segurança dos fármacos, mediante a exigência de apresentação pelos fabricantes de extensos estudos pré-clínicos farmacológicos e toxicológicos e estudos clínicos bem controlados. Ademais, a emenda determinou a revisão da eficácia de todos os produtos aprovados entre 1938 e 1962; disso resultou o Drug Efficacy Study Implementation, desenvolvido pela National Academy of Sciences, que recentemente concluiu o trabalho, resultando na remoção de mil hares de produtos ineficazes e de associações em doses fixas (Strom, 1994a). Associações em doses fixas são combinações de duas ou mais substâncias ativas na mesma fórmula.

Na área hospitalar, o FDA começou, a partir de 1960, a coletar os registros de reações adver- 
sas e a patrocinar programas de monitoramento de fármacos (Davies, 1987). Nas universidades iniciou-se a vigilância de antibióticos e de anticoagulantes. Estudos prospectivos pioneiros esti maram a incidência de reações adversas durante a internação na faixa de $10 \%$ a $15 \%$; ademais, $5 \%$ dos pacientes eram internados com reações adversas, sendo a maioria delas responsável pela internação (Seidl et al., 1965, 1966; Hurwitz, 1969). Atualmente, a Joint Commmission on Accreditation of Health Care Organizations requer que cada hospital ten ha um programa de monitoramento de reações adversas e um programa de avaliação do uso de fármacos (Strom, 1994b).

No Brasil, nas décadas de 60 e 70, o Serviço Nacional de Fiscalização da Medicina e Farmácia e a Comissão de Biofarmácia do Ministério da Saúde proscreveram ou restrigiram vários produtos, tais como: acetato de medroxiprogesterona de uso intramuscular, óleo de vaselina de uso nasal, arsenicais inorgânicos, procaína oral, cálamo, sais de cobalto, penicilina tópica, sulfato de neomicina em preparações extemporâneas, clorpromazina associada a dipirona e aminopirina, metiltestosterona de uso oral, silicone líquido, sulfas, cromatos e bicromatos de uso tópico, anticoncepcionais seqüenciais, cloranfenicol associado, naproxeno, corante Bordeuax S, alguns anti-helmínticos, sementes de cânhamo, hexaclorofeno de uso em mucosas e talidomida. Nas décadas de 70 e 80, a Câmara Técnica de Medicamentos do Conselho Nacional de Saúde impôs restrições a: uretana, carbamato de etila, clorofórmio, dihidroestreptomicina, fernormin em associação, estrógeno-progestágeno para diagnóstico da gravidez, vitaminas em produtos dietéticos, níveis de ciclamato e sacarina em produtos edulcorantes. Na década de 80, o Conselho Federal de Entorpecentes impôs restrições aos produtos com substâncias estimulantes do sistema nervoso central.

Além dos atos normativos específicos, surgiu a legislação geral que vigora até hoje. Destacam-se duas leis. A Lei no 5.991/ 1973 dispõe sobre o controle sanitário do comércio de drogas, medicamentos, insumos farmacêuticos e correlatos e prevêa colheita periódica de materiais e a interdição do estoque em estabelecimentos suspeitos de fraude. A Lei no 6.360/ 1976 regula os atos relacionados à cadeia de produção desde a fabricação até a propaganda; determina a transmissão à autoridade san itária competente dos acidentes ou reações nocivas, define produto alterado, adulterado ou impróprio para o consumo e tipifica as infrações (MS, 1978).
No plano internacional, acumularam-se iniciativas nas últimas décadas. A garantia de qualidade das especialidades farmacêuticas tem estado presente nas estratégias de integração da Comunidade Econômica Européia, embora motivada por razões de ordem econômica. Desde 1965, representantes dos paísesmembros elaboram normas para harmonizar dispositivos legais e reguladores. Difundiu-se para todos os países a obrigatoriedade da autorização pré-comercialização, posterior à comprovação pelo fabricante da qualidade, da inocuidade e da eficácia, mediante os resultados dos ensaios e dos testes experimentais e clínicos (Ministério de Sani dad y Consumo, 1984). A Organização Mundial da Saúde organizou encontros regionais e globais entre as agências regulamentadoras dos vários países e entre os pesquisadores das universidades e dos centros de investigação. Deve-se também registrar a sua recomendação para limitar o uso àqueles medicamentos de eficácia e segurança comprovadas, com os menores custos e que atendam ao leque mais amplo de necessidades sanitárias (WHO, 1977). A ONU publica, desde 1982, uma lista cumulativa das substâncias que sofreram restrições à comercialização por razões de segurança, nos últimos trinta anos, onde figura o nome dos países responsáveis pela decisão e as justificativas. Ela contém hoje cerca de trezentos princípios ativos (United Nations, 1991).

Importantes estudos destinados a avaliar a dimensão do problema nos países subdesenvolvidos têm sido realizados. A OMS, em 1983, promoveu o encontro de autoridades dos países asiáticos para discutir a regulamentação de fármacos, no qual sugeriu-se agregar à legislação elementos referentes ao monitoramento de reações adversas e à compensação para as vítimas dos fármacos (Jayasuriya, 1985). Posteriormente, a OMS patrocinou um inquérito para avaliar os resultados do Programa de Ação de Medicamentos Essenciais e da Implantação da Lista de Medicamentos Essenciais em 104 países subdesenvolvidos; os resultados mostraram que o controle de qualidade laboratorial existia em $70 \%$ dos países, embora na mai oria deles não funcionasse adequadamente; $65 \%$ do países não possuíam mecanismos de monitoramento de reações adversas e 19\% possuíam mecanismos assistemáticos (WHO, 1988). O Office of Technol ogy Assessement, órgão do Congresso norte-americano, realizou um inquérito para examinar as práticas usuais de rotulagem - na qual a bula é o componente mais importante - das companhias farmacêuticas norte-americanas em países subdesen- 
volvidos, incluindo o Brasil; foram analisados os impressos de 273 produtos correspondentes a 18 grandes empresas. Como resultado, constatou-se o comportamento diferenciado conforme sejam dirigidos a países do primeiro mundo ou subdesenvolvidos. No campo dos efeitos adversos, 25\% do material apresentaram problemas, entre os quais $59 \%$ foram considerados graves, como, por exemplo, a ausência de alerta quanto à agranulocitose ou à Síndrome de Stevens-Johnson (OTA, 1993).

Resumindo, pode-se afirmar, como Lee \& Herzstein (1986), que os fármacos estão entre os produtos mais pesadamente regulamentados da sociedade. Isso se deve, em parte, ao impacto da difusão dos eventos adversos. Embora o impulso inicial da regulamentação tenha derivado da necessi dade de normatizar a competição entre os fabricantes, quanto aos nomes de marca, por exemplo, ela evoluiu posteriormente para a proteção dos consumidores contra as fraudes e para a incorporação dos resultados dos estudos epidemiológicos.

Há um debate recorrente que coloca, de um lado, argumentos combaten do a 'mão pesada' do Estado, tais como: os el evados custos industriais para a pesquisa e o desenvolvimento de novos fármacos; a restrição à liberdade de produção e de prescrição de novidades terapêuticas e o atraso tecnológico gerado pela demora na concessão governamental da licença para comercialização. Do outro lado, há o entendimento de que o reforço às agências regulamentadoras é o antídoto mais eficaz para combater os efeitos danosos dos medicamentos, sejam eles o resultado de fraude, negligência ou insuficiência do conhecimento científico. Nesta linha de argumentação, recomenda-se: a difusão das informações clínico-farmacológicas; os registros sistemáticos das reações adversas; o desenvolvimento de sistemas de vigilância pós-comercialização; a necessidade de basear as decisões terapêuticas em ensaios clínicos controlados e em estudos observacionais bem desenhados.

Entretanto, basta dar uma olhada no alentado volume de substâncias que sofreram restrições nas últimas décadas e nas respectivas justificativas, ou então observar a freqüência e o perfil das reações adversas, sobretudo em grupos populacionais mais vulneráveis, para fazer a balança pender inexoravelmente para o segundo grupo de argumentos.

Apesar dos custos econômicos do investimento na regulamentação de fármacos é preciso compreender, como Lee \& Herzstein (1986), que "the potencial benefits and hazards of modern drugs are too important to be left to the marketplace and the unregulated functioning of the pharmaceutical industry". Ou, se nenhum destes argumentos for suficiente, é bom lembrar que, por mais rigorosos que sejam os ensaios clínicos e os estudos observacionais, por mais racionais que sejam as prescrições e por mais éticos que sejam os que prescrevem, dispensam, transportam ou vendem medicamentos, ainda assim, estamos diante de substâncias cujos riscos de efeitos tóxicos não podem ser totalmente eliminados ou, às vezes, sequer conhecidos.

\section{Classificação e mecanismos de produção de reações adversas}

Não há substância química totalmente segura ou totalmente tóxica. O dimensionamento do risco requer a compreensão dos mecanismos de produção dos efeitos tóxicos que embasam as classificações.

No Brasil, um dos pioneiros no estudo das reações adversas foi o professor Paulo Dias da Costa, que publicou um trabal ho sobre alergia à penicilina em 1948e, posteriormente, sintetizou classificações antigas de reações adversas (Costa \& Souza, 1985). Nessa síntese, observase que os efeitos indesejáveis mais conhecidos eram as manifestações alérgi cas e por isso as primeiras classificações enfatizavam este mecanismo; mas havia autores que, no início da década de 40, alertavam para o erro de atribuir todas as manifestações indesejáveis às alergias e levantavam outras possibilidades, tais como os efeitos tóxicos, os efeitos cumulativos, a hipersensibilidade, os processos desconhecidos ou a combinação desses mecanismos. Ainda segundo Costa \& Souza (1985), Naranjo, em 1965, apresentou uma classificação baseada nos seguintes grupos: reações do tipo tóxico intoxi cações e idiossincráticas; efeitos colaterais ou secundários - o mesmo efeito produzido por distintas drogas ou efeitos produzidos por um mesmo grupo farmacodinâmico; reações por hábito - dependência física ou psíquica; reações por sensibilização - alérgicas, anafiláticas ou por liberação de histamina; reações fotoinduzidas; reações teratogênicas ou embriotóxicas.

Há uma classificação que, embora didática, tem escassa aplicabilidade prática clínica ou epidemiológica, além de dificultar o enquadramento de certos tipos de reação, como, por exemplo, a teratogênica: 1) superdosagem relativa - resulta da concentração superior de um fármaco administrado em doses normais, por razões farmacocinéticas; 2 ) efeitos colaterais - 
são inesperados e inerentes à própria ação farmacológica; 3) efeitos secundários - são conseqüência do efeito desejado mas não se relacionam à ação farmacológica principal; 4) idiossincrasia - é uma sensibilidade peculiar a um produto motivada pela estrutura do sistema enzimático e geralmente de base genética; 5) hipersensibilidade alérgica - ocorre após a sensibilização prévia mediada por mecanismo imunológico; 6) tolerância - é o fenômeno pelo qual a administração repetida na mesma dosagem diminui a intensidade dos efeitos (Capellà $\&$ Laporte, 1989). Comparando esta classificação com a de Naranjo, nota-se que as reações idiossincráticas e as intoxicações não figuram mais no mesmo grupo; isto é compreensível, pois o avanço no campo da genética real ça as idiossincrasias como explicação dos eventos indesejáveis.

Atualmente, a classificação mais empregada é a de Rawlins e Thompson (Davies, 1987), que agrupa as reações adversas naquelas que são ações farmacológicas normais, porém aumentadas (tipo A), e nas que são efeitos dos fármacos totalmente anormais, bizarros (tipo B). As reações do tipo A são farmacologicamente possíveis de prever, são dose-dependente, têm altas inci dência e morbidade, baixa mortali dade e podem ser tratadas ajustando-se a dose. As reações do tipo B não são farmacologicamente previsíveis, não são dose-dependente, têm incidência e morbidade baixas, alta mortalidade e devem ser tratadas com suspensão do fármaco.

Reações adversas do tipo A (aumentada) Ocorrem por causas farmacêuticas; farmacocinéticas, ligadas ao modo anormal pelo qual o organismo de al guns indivíduos 'conduzem' os fármacos; farmacodinâmicas, determinadas por fatores genéticos ou doenças que al teram a sensibilidade dos órgãos-alvo. A bradicardia com os -bloqueadores adrenérgicos, a hemorragia com os anticoagulantes ou a sonolência com os benzodiazepínicos são reações do tipo A. Às vezes, a ação farmacológica primária do fármaco ocorre num órgão ou tecido que não é aquele para o qual estava destinado; é o caso da úlcera péptica e hemorrágica com os antiinflamatórios não esteróides ou da osteoporose com os glicocorticóides. Muitas delas ocorrem graças a uma propriedade da substância não relacionada ao efeito terapêutico: algumas fenotiazinas, muitos anti-histamínicos $\mathrm{H}$ e a maioria dos antidepressivos tricíclicos têm propriedades anticolinérgicas que resultam numa reação do tipo atropina com boca seca, dificuldade de acomodação visual e retenção urinária. O mesmo ocorre com as propriedades antian- drogênicas da cimetidina, a ação de bloqueio neuromuscular dos aminoglicosídeos ou a teratogenicidade da talidomida. Pode haver variabilidade individual com a administração da mesma quantidade de fármaco. Isso ocorre, por exemplo, com o salicilato: observa-se pequeno sangramento gastrintestinal, facilmente compensado, em praticamente todas as pessoas, após a ingestão de uma única dose de aspirina, mas alguns indivíduos perdem quantidades apreciáveis de sangue, podendo desenvolver anemia franca por deficiência de ferro. O zumbido ocorre em todos os que tomam doses elevadas de aspirina; a susceptibilidade individual a este sintoma, entretanto, é muito grande - a para produzi-lo varia de $3 g$ a 29g (Davies, 1987).

Reações adversas do tipo B (bizarras) - Caracterizam-se por alguma diferença qualitativa no fármaco, no paciente ou em ambos. As reações do tipo B por causas farmacêuticas ocorrem por: decomposição de constituintes ativos; efeito de aditivos, solubilizantes, estabilizantes, corantes e excipientes; efeitos de produtos secundários aos constituintes ativos, provenientes do processo de fabricação. A tetraciclina, quando armazenada em temperaturas elevadas, degrada-se, transformando-se numa massa viscosa marron e produz uma síndrome do tipo Fanconi com aminoacidúria, glicosúria, acetonúria, albuminúria, piúria, elevação do -aminonitrogênio plasmático e fotossensibilidade. O propilenoglicol usado como solvente em fármacos injetáveis pode ser parcialmente responsabilizado pela hipotensão que se segue à injeção endovenosa de fenitoína. As reações por causas farmacocinéticas, isto é, anormalidades na absorção, na distribuição ou na eliminação, são escassas, poisa absorção e a distribuição são predominantemente processos passivose anormalidades na eliminação podem surgir quando o metabolismo de um fármaco origina um metabolito novo e raro. Nas causas farmacodinâmicas, fatores como peso, idade, sexo, via e tempo de administração influenciam a resposta dos órgãos-alvo a um dado fármaco, produzindo diferenças quantitativas nas respostas. A presença de doença pode resultar em diferenças qualitativas ou quantitativas, sendo que as primeiras podem ser genéticas, imunológicas, neoplásicas ou teratogênicas. Entre as causas genéticas, uma das mais conhecidas é a deficiência de glicose-6-fosfato desidrogenase, que resulta em hemólise e envolve um grande número de fármacos, tais como, as aminoquinolonas, as sulfonamidas e sulfonas, os nitrofuranos, os analgésicos (incluindo a aspirina) (Davies,1987). Entre as causas imunológicas estão: 
as anemias hemolíticas induzidas por penicilina; a anemia hemolítica auto-imune induzida por metildopa; a púrpura trombocitopênica induzida por quinidina; a granulocitopenia induzida por sulfonamida e o lupus eritematoso sistêmico induzido por procainamida ou por hidralazina (Goodman \& Gilman's, 1996). No que se refere às reações neoplásicas e as teratogênicas, é preciso considerar que uma resposta qualitativamente anormal a um fármaco pode ocorrer pela presença de tecido potencialmente neoplásico ou teratológico no organismo (Davies, 1987).

\section{Diagnóstico das reações adversas}

Esta é uma das questões mais problemáticas da área. A dificuldade para decidir se um determinado quadro clínico foi induzido por um fármaco pode ser ilustrada com o estudo de eventos suspeitos a partir dos resumos médicos de alta hospitalar: quinhentos deles foram avaliados por três farmacologistas clínicos usando definições explícitas e testadas de reações adversas, e em apenas um quinto dos casos os registros estavam indubitavelmente corretos (Davies, 1987). Na verdade, a fal ta de uniformidade no diagnóstico se esten de por toda a prática médica. O diagnóstico de reações adversas é apenas um caso particular de diagnóstico diferencial, onde o fator implicado é uma substância paradoxalmente indicada para curar. Um dos elementos-chave para o entendimento das diferenças entre os diagnósticos de vários clínicos para um mesmo caso é a subjetividade presente nos processos de decisão diagnóstico e terapêutico.

Procurando compreender as diferenças na preferência dos médicos entre várias opções terapêuticas, Denig et al. (1993) concluíram que um modelo de decisão que inclui apenas valores e expectativas biomédicas é capaz de predizer o tratamento em não mais do que $53 \%$ dos casos; a inclusão de aspectos sociais, tais como a aprovação dos colegas e dos pacientes e a experiência, sobretudo a própria, aumentam a capacidade de previsão do modelo para $77 \%$. O mesmo estudo revelou uma grande variação nas expectativas quanto às reações adversas: $94 \%$ de todas elas foram citadas por menos de $50 \%$ dos entrevistados.

A inconsistência das decisões médicas entre os profissionais levou à busca de critérios objetivos para diagnosticar as reações adversas. Surge o algoritmo de Karch \& Lasagna (1977), apresentado no formato de três tabelas de decisão:
1) exclusão dos envenenamentos, dos suicídios e do não-cumprimento da prescrição;

2) aplicação de cinco critérios: seqüência temporal apropriada, curso clínico consistente com o efeito conhecido de doenças ou de terapias não farmacológicas, curso clínico consistente com o efeito conhecido do fármaco, efeito da redução ou da suspensão da dose e efeito do reinício da terapia. De acordo com esses elementos, a reação é classificada como definida, provável, possível, condicional ou não relacionada.

3) identifica as causas: cumprimento atípico da prescrição, erro de prescrição, interação, doença terminal, uso do fármaco apropriado.

O algoritmo foi testado por meio do estudo de pacientes internados com suspeita de reação adversa, comparando-se o laudo elaborado por três farmacologistas clínicos com o algoritmo aplicado por um investigador independente, havendo concordância em $71 \%$ dos casos. O método, embora confira objetividade ao diagnóstico, é inútil para identificar as reações desconhecidas e não fornece critérios para julgamentos individuais ou dados para a reprodutibilidade da avaliação (Karch \& Lasagna, 1977).

Outros autores criaram um método semeIhante denominado imputabilidade, com dois componentes; imputalibidade intrínseca, sustentada nos critérios do algoritmo citado acima, acrescido de exames complementares, características constitucionais ou congênitas e antecendentes patológicos; e imputabilidade extrínseca, baseada na literatura. Atribuem-se pontos a cada um dos critérios a fim de criar combinações númericas que descrevem nove situações. Uma delas enquadra uma reação como verossímil, segundo as características do caso, e como duvidosa, segundo a literatura, o que sugere uma reação adversa nova. A complexidade do método pode ser ilustrada com as possíveis situações intermediárias quanto à regressão dos sintomas com a suspensão do tratamento: a tardia; a provocada por tratamento corretivo com enfraquecimento da relação entre o sintoma e o medicamento e a regressão irreversível, como na surdez por aminoglicosídeos (Dangoumau et al., 1978).

No final da década de 70, surge um novo algoritmo empregando os mesmos critérios anteriormente citados, acrescido do "nível do fármaco e evidência desuperdosagem" (Kramer et al., 1979). A reprodutibilidade e a validade do algoritmo foram testadas (Hutchinson et al., 1979) em trinta casos hospitalares de suspeita de reações adversas; três profissionais não especializados em farmacologia clínica aplica- 
ram um questionário com 56 perguntas derivadas do algoritmo e concordaram com a probabilidade atribuída à reação em $67 \%$ dos casos, com concordância entre os pares variando de $73 \%$ a $87 \%$. Ademais, dois farmacologistas clínicos avaliaram os casos e concordaram em $47 \%$ das vezes quando não empregaram o algoritmo, e em $63 \%$ quando o empregaram. A maior fonte de discordância consistiu no julgamento das alternativas etiológi cas. Este mesmo algoritmo foi submeti do a testes por Leventhal et al. (1979) com oito clínicos que revisaram trinta casos implicitamente e dois meses depois aplicando o algoritmo; a reprodutibilidade da avaliação dos clínicos mais experientes melhorou, embora a melhora na avaliação dos internos não tenha si do estatisti camente significante.

$\mathrm{Na}$ busca de métodos mais simples para uso de não-especialistas, Naranjo et al. (1981) criou uma escala de probabilidades com dez perguntas e respostas do tipo sim-não, baseadas nos critérios tradicionais de avaliação de reações adversas. Dois médicos e quatro farmacêuticos julgaram independentemente 63 supostas reações. Após seis e 22 semanas, reavaliaram usando a escala de probabilidades e estimaram os coeficientes de concordância, bem como a validade consensual, de conteúdo e concorrente, tendo concluído que os valores obtidos eram altos e que o método oferecia uma alternativa sensível de monitoramento. Como no caso anterior, a mai or fonte de discordância foi a avaliação das causas alternativas.

$\mathrm{Na}$ década de 80 , os esforços para aprimorar o diagnóstico de reações adversas continuaram. O método de imputabilidade foi testado por Begaud et al. (1982) através da revisão de duas mil observações de um centro de farmacovigi lância e da identificação do número de vezes em que cada critério era atribuído sem ambigüidade. Em mais da metade dos casos (52\%), a estimativa global repousou em apenas dois critérios - a cronologia e a bibliografia.

Concluindo, é possível afirmar que os diferentes métodos não evitam a subjetividade das decisões médicas, porém diminuem as dúvidas. Os critérios propostos por Karch \& Lasagna (1977) serviram de base para as tentativas subseqü entes; entre eles, a reexposi ção raramente é feita por razões de ordem ética e o timing e a bibliografia têm sido os mais úteis. Os méto dos que atribuem pontos a cada critério são mais vantajosos, pois permitem a comparação entre scores de dois ou mais fármacos suspeitos e a medição da reprodutibilidade. Os algoritmos permitem estabelecer dados de in- cidência mais acurados, facilitam as atividades epidemiológica e de monitoramento e a tomada de decisão política. Entretanto, a comparação entre os distintos estudos nem sempre éfácil, já que há diferenças entre as características das populações submetidas aos inquéritos, entre as técnicas empregadas e entre os critérios e as definições. O julgamento clínico e a experiência são fundamentais para o uso do algoritmo; segundo Hutchinson et al. (1979), sua utilidade maior reside nos estudos de avaliação da toxicidade de fármacos individuais. O uso do algoritmo pode melhorar com o manual de instruções e com o conhecimento da lógica que presidiu a sua construção (Leventhal et al., 1979).

\section{Perspectivas atuais da farmacovigilância}

Retomando a questão da criação de sistemas de monitoramento de reações adversas em nosso meio, têm-se agora elementos para discutir o panorama no campo da farmacovigilância. Conceitualmente ela pertence à Farmacoepidemiologia ou Epidemiologia dos Medicamentos, e pode ser denominada vigilância póscomercialização. Entre seus objetivos destacam-se: a determinação da freqüência dos eventos adversos e dos fatores de risco e a detecção precoce de reações novas e graves. A descrição pormenorizada dos seus métodos e técnicas escapa aos objetivos do presente trabalho, mas são acessíveis nos livros e coletâneas citados.

Com relação à sua necessidade, muito se tem dito a respeito da insuficiência dos ensaios clínicos controlados pré-comercialização para detectar reações adversas. Eles possuem o poder conferido pela randomização, que é o de evitar o confundimento pela indicação e tornar os grupos comparáveis (Greenland \& Morgenstern, 1988; Miettinen, 1989), porém possuem algumas fraquezas. Como expressou Rogers (1989), eles padecem dos cinco 'muitos': muito poucos, muito simples, muito idade 'média', muito estreitos e muito curtos. Isso significa que o número de pacientes expostos é pequeno, aqueles com complicações ou em uso de outras terapi as são excluídos, os muito idosos e os muito jovens não participam, as indicações expressas nos protocolos são bem definidas e o tempo de experimentação costuma ser muito curto. Tais condições não expressam nem de longe o que se passa no cotidiano da terapia farmacológica.

Na medida em que cresce a consciência dos profissionais de saúde com respeito às insufi- 
ciências apontadas acima, amplia-se o interesse pelos estudos pós-comercialização. Impulsiona também este interesse a descoberta dos efeitos latentes ou que aparecem após o uso prolongado, dos modificadores da eficácia, e dos demais elementos que definem a eficiência de um tratamento. Na avaliação das condições para o desenvolvimento de sistemas da farmacovigilância, um dos tópicos que merece destaque é a obtenção das informações.

Nos Estados Unidos, al ém dos sistemas de registros espontâneos, estão disponíveis os seguintes bancos de dados: populacionais; dos programas de atenção à saúde; coletados continuamente para estudos de farmacoepidemiologia; previamente coletados como parte de estudos ad hoc; coletados ad hoc para estudos de farmacoepidemiologia (Strom, 1991). Cada um apresenta vantagens e desvantagens e, em conjunto, permitem cobrir um amplo leque de opções metodológicas e de objetivos. Exemplificando, o sistema de notificações espontâneas é útil para identificar reações raras ou novas (Biriell \& Olsson, 1989); os conjuntos de dados populacionais são preciosos para identificar tendências seculares (Katschinski \& Logan, 1991). Ademais, há novos métodos de detecção baseados em dados coletados na rotina dos serviços de saúde, tais como a revisão diária e sistemática dos diagnósticos de um serviço de urgência, usando uma lista de diagnósticos suscetíveis de ser reações adversas (Armadans et al., 1988; Ibañez et al., 1991).

No Brasil, algumas destas fontes, como os bancos de dados populacionais, dos programas de atenção à saúde ou das contas hospitalares, não dispõem de registros do uso de medicamentos. Eventualmente, os programas de assistência farmacêutica em sistemas locais de saúde possuem informações sobre a distribuição de fármacos, mas é incomum encontrar as variáveis de uso de fármacos associados às variáveis de morbidade ou sócio-econômicas, de tal forma que se possam estimar os riscos associados às exposições. Apesar das lacunas, existem em nosso meio sistemas de registros de eventos adversos (não relacionados apenas ao uso de medicamentos) com experiência acumulada, e alguns estudos de Farmacoepidemiologia, como se verá adiante.

Um importante sistema com fluxo contínuo de informações é o Sistema Nacional de Informações Tóxico-Farmacológicas (Sinitox). Foi constituído em 1980 e divulga anualmente os casos de intoxicações e envenenamentos humanos provenientes de 31 centros regionais. Até 1995 estavam registrados 386.861 casos; dentre estes, os ocasionados por medicamen- tos estão em segundo lugar, sendo seguidos pelos acidentes com animais peçonhentos (Bortoletto, 1997). Segundo uma avaliação recente (Marques et al., 1993), trata-se de um sistema complexo, em construção, limitado, entre outros fatores, pela subnotificação, dado que um grande número de casos é registrado na rede de serviços de saúde. Como é um sistema voltado para as intoxicações, o registro dos problemas relacionados ao uso terapêutico de fármacos possivelmente não aporta a ele.

Um outro sistema permanente é o Estudo Colaborativo Latino-Americano de Malformações Congên itas (Eclamc), que registra os nascimentos hospitalares na região para investigar fatores de risco para malformações congênitas; foi criado em 1967 e já diagnosticou mais de 75.000 delas. Funciona no Brasil desde 1972, sediado na Fiocruz (Castilla et al., 1994). Entre as diretrizes para a prevenção primária dos defeitos congênitos, preconiza monitorar vários agentes, entre eles, os medicamentos; para isso, recomenda coletar dados de uso de fármacos durante a gravidez, registrando o nome, a dose, a indicação e a semana de gravidez da exposição (Castilla et al., 1991). Trata-se de um sistema da maior relevância para a saúde pública, embora restrinja-se no campo dos fármacos à identificação das reações teratogênicas e mutagênicas.

Como ilustração de ações de monitoramento temporário, é interessante citar a experiência de vigilância dos efeitos do tratamento da hanseníase com múltiplos fármacos, desenvolvida pelo Programa de Controle da Hanseníase da Secretaria de Saúde do Estado de São Paulo. Foi criado um fluxo de informações entre os diversos níveis do sistema que registrou as reações durante trinta meses, em 550 unidades de saúde (Brasil et al., 1996). A despeito da possível subnotificação, o sistema chamou a atenção dos médicos participantes para esses eventos (Brasil, 1997).

Quanto aos dados coletados especificamente para estudos de Farmacoepidemiologia, têm sido realizados alguns trabal hos com distintas abordagens, como, por exemplo, estudos transversais (Fuchs et al., 1977); observação de coortes de usuários (Koifman et al., 1987); análise de série de casos (Fonseca et al., 1991); estratégias de casos e controles (Rozenfeld, 1997).

Um vez constatada a existência em nosso meio de experiência acumulada, resta indagar das condições materiais de viabilização de um sistema permanente de notificação de reações adversas e de investigação epidemiológica da ocorrência e dos fatores associados às reações adversas. Para que tais ações não ocorram em 
caráter episódico, é importante que sejam institucionalizadas em Centros de Informação sobre Medicamentos (CIM), criando um ambiente favorável e culturalmente transformador. Segundo o trabalho desenvolvido no Conselho Federal de Farmácia (Vidotti, 1997), os CIMs consistem em um servi ço prestado à comunidade, sendo sua principal meta o uso racional de medicamentos. Diferentemente das bibliotecas e dos centros de documentação, os CIMs não se limitam a proporcionar documentos ou referências bibliográficas, mas soluções para problemas concretos sobre medicamentos. Suas funções são: responder perguntas, revisar o uso de fármacos, elaborar publicações, realizar atividades educativas, de pesquisa e de coordenação de programas de notificação. Segundo o mesmo autor, vem sendo estruturada no País uma rede (Sismed) que possui dez CIMs, cujo objetivo é potencializar a troca de informações e de experiências, além de desenvolver projetos colaborativos de investigação; alguns deles, sediados em universidades, estão iniciando atividades de notificação espontânea, como os da Universidade Federal do Ceará, da Universidade Federal de Mato Grosso e da Universi dade Estadual de Maringá (Socie-

\section{Agradecimentos}

Agradeço as valiosas sugestões e opiniões do Prof. Dr. Luis Antonio Bastos Camacho, da Escola Nacional de Saúde Pública, Fundação Oswaldo Cruz.

\section{Referências}

ARM ADANS, L.; CARNÉ, X. \& LAPORTE, J. R., 1988. Detección de reacciones adversas a medicamentos a partir del diagnóstico de ingreso hospitalario. Método y resultados. Medicina Clinica, 91: 124-127.

ARRAIS, P. D. S., 1995. Farmacovigilância no Brasil. Boletim Farmacológi co-GPUIM - Grupo de Prevenção ao Uso Indevi do de Medicamentos, 4:3.

BEGAUD, B.; HARAM BURU, F.; PÈRE, J. C. \& DANGOUMAU, J., 1982. Les critères d'imputabilité confrontés à la pratique: a propos de 1000 observations. Thérapie, 37:415-420.

BIRIELL, C. \& OLSSON, S., 1989. O programa de farmacovigilância da OMS. In: Epidemiologia do Medicamento (J. R. Laporte, G. Tognoni \& S. Rozenfeld, orgs.), pp. 153-176, Rio de Janeiro: Abrasco/Hucitec. dade Brasileira de Vigilância de Medicamentos, 1997).

Concluindo, é possível assegurar que há condições para que a Portaria SVS no 40 de 09/ 05/ 95 seja plenamente implantada nos próximos anos. Só não o será se preponderarem mais uma vez os vícios do campo da Vigilância Sanitária, que têm sido sobretudo de natureza política, como já foi apontado anteriormente (Luchesi, 1992; Souto, 1996). Segundo Waldman (1991), têm preponderado desde a sua criação os aspectos burocráticos sobre os técnicos, desconsiderando-se as atividades de pesquisa, a vigilância de eventos adversos, a monitorização da qualidade dos produtos, dos insumos e dos serviços e a orientação sanitária. Espera-se que a estruturação do campo de vigilância em saúde (OPAS, 1994) no contexto da descentralização dos serviços e o advento da nova Portaria possam propiciar novas práticas no setor. O volume de informação hoje disponível é de tal magnitude, que dificilmente justifica-se que um país com a qualificação científico-tecnológica do Brasil não possua programas permanentes de farmacovigilância e um sistema nacional de notificação de reações adversas.
BORTOLETTO, M. E., 1997. Estatística Anual de Casos deIntoxi cação e Envenenamento. Brasil, 1995. Rio de Janeiro: Multimeios/CICT/Fiocruz.

BRASIL, M. T. L. B. F.; OPROM OLLA, D. V. A.; M ARZLIAK, M. L. C. \& NOGUEIRA, W., 1996. Results of a surveillance system for adverse efects in Leprozy's WHO/MDT. International Journal of Leprosy, 64:97-104.

BRASI L, M. T. L. F. B., 1997. Comunicação Pessoal.

CAPELLÀ, D. \& LAPORTE, J. R., 1989. Mecanismos de produção e diagnóstico clínico dos efeitos indesejáveis produzidos por medicamentos. In: Epidemiologia do Medicamento (J. R. Laporte, G. Tognoni \& S. Rozenfeld, orgs.), pp. 115-124, Rio de Janeiro: Abrasco/Hucitec.

CASTILLA, E. E.; LOPEZ-CAMELO, J. S.; DUTRA, G. P. $\& P A Z$, J. E., 1991. Birth defects monitoring in un- 
derdeveloped countries: an example from Uruguay. International Journal of Risk \& Safety in Medicine, 2:271-288.

CASTILLA, E. E.; PAZ, J. E.; ORIOLI, I. M .; LOPEZCAMELO, J. S. \& DUTRA, G. P., 1994. EI ECLAMC: Estudio colaborativo latinoamericano de malformaciones congénitas. Mendeliana, 11(Supl.):811.

COSTA, P. D. \& SOUZA, S. A. A. M., 1985. Sobre as reações adversas aos medicamentos. Fixação de conceitos. Arquivos Brasileiros de Medicina, 59: 439-441.

DANGOUMAU, J.; EVREUX, J. C. \& JOUGLARD, J., 1978. Méthode d'imputabilité des effects indésirables des medicaments. Thérapie, 33:373-381.

DAVIES, D. M., 1987. Textbook of AdverseDrug Reactions. Oxford: Oxford University Press.

DENIG, P.; HAAIJER-RUSKAMP, F. M.; WESSELING, H. \& VERSLUIS, A., 1993. Towards understanding treatment preferences of hospital phisicians. Social Sciences and Medicine, 36:915-924.

FONSECA, W.; ALENCAR, A. J. C.; MOTA, F. S. B. \& COELHO, H. L. L., 1991. Misoprostol and congenital malformations. Lancet, 338:56.

FUCHS, F. D.; TED OLDI, C.; BANDEIRA DE MELLO, A. A. \& SOARES, A. C., 1977. Efeitos indesejáveis de fármacos: um estudo da incidência em nosso meio. Revista AMRIGS, 21:101.

GOODMAN \& GILMAN'S, 1996. The Pharmacological Basis of Therapeutics. New York: McGraw Hill.

GREENLAND, S. \& MORGENSTERN, H., 1988. Classification schemes for epidemiologic research designs. Journal of Clinical Epidemiology, 41:715716.

GUEDES, M. L. F., 1990. Histórico da Vigilância Sanitária. Monografia do Curso de Especialização em Vigilância Sanitária, Curitiba: Escola de Saúde Pública do Paraná.

HURWITZ, N., 1969. Predisposing factors in adverse reactions to drugs. British Medical Journal, 1:531540.

HUTCHINSON, T. A.; LEVENTHAL, J. M.; KRAMER, M. S.; KARSCH, F. E.; LIPMAN, A. G. \& FEINSTEIN, A. R., 1979. An algorithm for the operational assessment of adverse drug reactions. Part II - Demonstration of reproducibility and validity. Journal of American Medical Association, 242:633-638.

IBAÑEZ, L.; LAPORTE, J. R. \& CARNÉ, X., 1991. Adverse drug reactions leading to hospital admission. Drug Safety, 6:450-459.

JAYASURIYA, D. C., 1985. Regulation of Pharmaceuticals in Devel oping Countries. Legal Issues and Approaches. Geneva: World Health Organization.

KARCH, F. E. \& LASAGNA, L., 1977. Toward the operational identification of adverse drug reactions. Clinical Pharmacology and Therapeutics, 21:247254.

KATSCHINSKI, B. D. \& LOGAN, R. F. A., 1991. Changes in birth-cohort pattern of peptic ulcer mortality in England and Wales. Post Graduate Medicine, 67:825-828.

KOIFMAN, S.; PAES, S. J. P.; OLIVEIRA, D. P.; VIANNA, N. F.; GIOVANINI, M. E.; CASTRO, M. L. O.; MOTA, L. G.; POYARES, J. A. M.; GOMES, F. M. P. \& CASTRO, A. M. M., 1987. Avaliação do anticon- cepcional Norplant no Município do Rio de Janeiro (Brasil). Revista de Saúde Pública, 21:513522.

KRAMER, M. S.; LEVENTHAL, J. M.; HUTCHINSON, T. A. \& FEINSTEIN, A. R., 1979. An algorithm for the operational assessement of adverse drug reactions. Parte I - Background, description, and instructions for use. Journal of American Medical Association, 242:623-632.

LEE, P. R. \& HERZSTEIN, J., 1986. International drug regulation. Annual Review of Public Health, 7: 217-235.

LEVENTHAL, J. M.; HUTCHINSON, T. A.; KRAMER, M. S. \& FEINSTEIN, A. R., 1979. An algorithm for the operational assessment of adverse drug reactions. III - Results of tests among clinicians. Journal of American Medical Association, 242:1.9911.994.

LOBATO, M., 1964. Mr. Slang e o Brasil eProblema Vital. São Paulo: Brasiliense.

LUCHESI , G., 1992. Vigilância sanitária: o el o perdido. Divulgação em Saúde Para Debate, 48-52.

MACHADO, R.; LOUREIRO, A.; LUZ, R. \& MURICY, K., 1978. Danação da Norma: A Medicina Social ea Constituição da Psiqui atria no Brasil. Rio de Janeiro: Graal.

MARQUES, M. B.; BORTOLETTO, M . E.; FREITAS, C. M.; BEZERRA, M. C. C. \& SANTANA, R. A. L., 1993. Intoxicações e envenenamentos aci dentais no Brasil: análise epidemiológica dos casos registrados pelo Sinitox. Informe Epidemiológico do SUS, 2:59-96.

MIETTINEN, O. S., 1989. Unlearned lessons from clinical trials: a duality of outlooks. Journal of Clinical Epidemiology, 42:499-502.

MS (Ministério da Saúde), 1978. Consultoria Jurídica. Legislação Federal do Setor Saúde. Brasília: M inistério da Saúde.

MINISTÉRIO DE SANIDAD Y CONSUMO, 1984. La Cooperaci on Internacional en Materia de Medicamentos. Madrid: Dirección General de Farmacia y Productos Sanitários.

NARANJO, C. A.; BUSTO, U.; SELLERS, E. M.; SANDOR, P.; RUIZ, I.; ROBERTS, E. A.; JANECEK, E.; DOMECK, C. \& GREENBLATT, D. J., 1981. A method for estimating the probability of adverse drug reactions. Clinical Pharmacology and Therapeutics, 46:239-245.

OPAS (Organização Pan-Americana de Saúde), 1994. Planejamento e Programação Local deVigilância Sanitária no Distrito Sanitário. Brasília: OPAS.

OTA (Office of Technology Assessment), 1993. Drug Labeling in Developing Countries. Washington, DC: U.S. Government Printing Office.

ROGERS, A. S., 1989. Adverse drug events: identification and attribution. In: Pharmacoepidemiology. An Introdution (A. G. Hartzema, M. S. Porta \& H. H. Tilson, eds.), pp. 13-18, Chapell Hill: Harvey Whitney Books.

ROSEN, G., 1994. Uma História da Saúde Pública. São Paulo: Unesp.

ROZENFELD, S., 1989. O uso de medicamentos no Brasil. In: Epidemi ol ogia do Medicamento (J. R. Laporte, G.Tognoni \& S. Rozenfeld, orgs.), pp. 2142, Rio de Janeiro: Abrasco/Hucitec.

ROZENFELD, S., 1997. Reações Adversas aos Medica- 
mentos na Terceira I dade: As Qu edas em Mulheres como Iatrogenia Farmacoterapêutica. Tese de Doutorado, Rio de Janeiro: Instituto de Medicina Social, Universi dade do Estado do Rio de Janeiro.

SEIDL, L. G.; THORNTON, G. F. \& CLUFF, L. E., 1965. Epidemiological studies of adverse drug reactions. American Journal of Public Health, 55: 1.170-1.175.

SEIDL, L. G.; THORNTON, G. F.; SMITH, J. W. \& CLUFF, L. E., 1966. Studies on the epidemiology of adverse drug reations. III. Reactions in patients on a general medical service. Bulletin of Johns' Hopkins Hospital, 119:299-315.

SOCIEDADE BRASILEIRA DE VIGILÂNCIA DE MEDICAMENTOS, 1997. In: Anais do IV Congresso Brasileiro deVigilância de Medicamentos, Brasília.

SOUTO, A. C., 1996. Saúde e Política - A Vigilância Sanitária no Brasil:1976-1994. Tese de Mestrado, Salvador: Instituto de Saúde Coletiva, Universidade Federal da Bahia.

STROM, B. L., 1991. Postmarketing surveillance and other epidemiologic uses of drug prescription data in the United States. Annali dell Istituto Superioredi Sanità, 27:235-238.

STROM, B. L., 1994a. What is pharmacoepidemiology. In: Pharmacoepidemiology (B. L. Strom, ed.), pp. 3-13, Chichester (England): Strom, B. L.

STROM, B. L., 1994b. Preface for second edition. In: Pharmacoepidemiology (B. L. Strom, ed.), pp. xvii, Chichester (England): Strom, B. L.
TOGNONI, G. \& LAPORTE, J. R., 1989. Estudos de utilização de medicamentos. In: Epidemiologia do Medicamento (J. R. Laporte, G. Tognoni \& S. Rozenfeld, orgs.), pp. 43-56, Rio de Janeiro: Abrasco/Hucitec.

UNITED NATIONS, 1991. Consolidated List of ProductsWhose Consumption and/or SaleHave Been Banned, Withdrawn, Severily Restricted, or Not Approved by Government. New York: United Nations.

VIDOTTI, C. C. F., 1997. Sistema Brasileiro de Informações sobre Medicamentos - Sismed. Texto distribuído no IV Congresso Brasileiro deVigilância deM edicamentos, Brasília.

WALDMAN, E. A., 1991. Vigilância Epidemi ológi ca como Prática de Saúde Pública. Tese de Doutorado. São Paulo: Faculdade de Sáude Pública, Universidade de São Paulo.

WHO (World Health Organization), 1972. International Drug Monitoring, the Role of National Centers. Report of a WHO Meeting. Geneva: WHO.

WHO (World Health Organization), 1977. Selección de Medicamentos Esenciales. Geneva: WHO. (Technical Report Series, 615)

WHO (World Health Organization), 1988. TheWorld Drug Situation. Geneva: WHO.

ZUBIOLI, A., 1992. Profissão Farmacêutico. E Agora? Curitiba: Editora Lovise. 
Debate sobre o artigo de Suely Rozenfeld

Debate on the paper by Suely Rozenfeld

Paulo Barragat

Associação Brasileira das Indú strias de Química Fina, Rio de Janeiro, Brasil.
Na página 243, a autora inicia o assunto com a assertiva: "Não há substância química totalmente segura ou totalmente tóxica". Considerando que em outras partes do trabalho há referências a citações mais antigas, caberia mencionar a famosa definição de Paracelso, alquimista e médico suíço do século XVI: “Tudo éve neno, dependendo da dose".

A partir da página 241, o artigo enumera dezenas de fármacos proscritos ou restritos, entre eles a talidomida. Quer me parecer que o caso da talidomida merece um destaque maior, em razão de sua importância terapêuti ca versus ação teratogênica. Apenas recordando, a talidomida foi desenvolvida pelo laboratório alemão Chemie Grumental, de Düssel dorf, e comercializada em 1954 com a finalidade de controlar a ansiedade e náuseas em gestantes. Em 1957 ela passou a ser consumida em 146 países, mas no início da década de 60 o consumo do medicamento por gestantes foi relacionado ao nascimento de crianças deformadas, bastando para tanto a ingestão de meio comprimido, além de a substância permanecer no organismo por dois anos. Consta que mais de dez mil crianças sofreram a ação teratogênica do fármaco. Ele foi banido de quase todos os países em 1961, e do Brasil em 1962. Quanto aos EUA, o Food and Drug Administration (FDA) nunca aprovou seu uso.

O Brasil, que à época não reconhecia patentes sobre fármacos e seus processos de obtenção, passou a sintetizar a talidomida em 1965, através da Sociedade Farmacêutica Brasifa, no Rio de Janeiro. O fármaco era exportado pela Interbrás para 38 países. Segundo relação publicada pelo Ministério da Saúde no D.O.U. de $21 / 11 / 85$, talidomida era também sintetizada pela Tortuga Companhia Zootécnica Agrária, Mairinque, São Paulo, que continua produzindo, segundo o Index Abiquif, 1995. Este relaciona ainda como fabricantes a Ecadil Indústria Química S.A., em Cosmópolis, São Paulo, e a Microbiológica Química Farmacêutica, no Rio de Janeiro. Dizo Ministério da Saúde que só a Fundação Ezequiel Dias (Funed), em Belo Horizonte, Minas Gerais, responsável pela distribuição do medicamento, está credenciada a formular a talidomida. Contudo, o Dicio- nário de Especialidades Farmacêuticas - DEF 97/98 - relaciona como medicamento à venda a Talidomida Brasifa, tubo com cinqüenta comprimidos de $100 \mathrm{mg}$.

Ano após ano, a talidomida vem comprovando sua eficácia para diferentes fins, como: evitar a rejeição de órgãos transplantados; ajudar no funcionamento adequado do sistema imunológico no combate às enfermidades; auxiliar na artrite reumatóide, no lúpus eritematoso, no mal de Behcet, no tratamento de ulcerações da mucosa oral dos aidéticos, no combate à perda de peso dos doentes de AIDS e de câncer; evitar o crescimento do sarcoma de Kaposi , do câncer da próstata e glioblastomas. Este é o exemplo de um medicamento que não pode ser banido e que, por isso mesmo, deve ser submetido ao mais rigoroso controle de uso. É o que procuram fazer o Ministério da Saúde, no Brasil, e o FDA nos EUA.

Na página 242, a autora diz que a Organização Mundial da Saúde (OMS) patrocinou um inquérito sobre a Implantação da Lista de Medicamentos Essenciais em 104 países subdesenvolvidos. Ora, o Brasil antecipou-se em muitos anos nessa in iciativa, o que acho indispensável mencionar, uma vez que, através do Decreto no 53.612, de 26 de fevereiro de 1964, o Presidente João Goulart “aprova a relação de medi camentos essenciais para fins previstos no Decreto no 52.471 e di spõe sobre aqui sição de medicamentos pela Administração Pública Fe deral". No entanto, só entre 11 e 13 de outubro de 1976, em Genebra, teve lugar a WHO Consultation on the Sel ection of Essential Drugs.

Em 24/08/77, o Ministro da Previdência e Assistência Social, por meio da Portaria PT-GM no 817/77, homologa a Relação de Medicamentos Básicos (RMB), elaborada pelo então Conselho Consultivo da Ceme. Mais tarde, considerando a seleção de medicamentos essenciais proposta pela OMS em 1977, o mesmo ConseIho Consultivo - o qual tive a honra de integrar - elaborou a atual Relação Nacional de Medicamentos Essenciais (Rename), aprovada pela Portaria Interministerial no 6 de 18/03/ 80. A edição mais recente da Rename é de 89/90. Consta que ela está sendo revista pelo Ministério da Saúde.

Em 1987, a Central de Medicamentos idealizou a Farmácia Básica, módulo-padrão de suprimento, composto por produtos selecionados da Rename, que permitem o tratamento das doenças mais comuns na população brasileira, no plano da atenção básica de saúde, em nível ambulatorial.

Em 7 de novembro de 1997, o Ministério da Saúde lançou, em Cachoeira do Arari, na Il ha 
de Marajó, Pará, o programa Farmácia Básica, o qual fornece trimestral mente kits com quarenta tipos de medicamentos para os postos de saúde de 4.171 municípios com menos de 21.00 habitantes, devendo beneficiar quarenta miIhões de pessoas. Os constituintes dos kits variam de acordo com as características epidemiológicas de cada região. Por exemplo, para as regiões de Belém, no Pará, e Recife, em Pernambuco, o kit deverá conter o fármaco dietilcarbamazina, indispensável para o tratamento da filariose.

Na página 247, a autora se refere à prevenção primária dos efeitos congênitos, monitorando vários agentes, entre eles, os medicamentos. Quero crer que aí caberia mostrar a vantagem de ser divulgada uma relação dos medicamentos com restrições às gestantes. Por exemplo, na Suécia, desde 1978, o catálogo de suas especialidades farmacêuticas contém uma seção intitulada: Pregnancy and breastfeeding. Na categoria A, estão listados aqueles que, tendo sido administrados em gestantes, nenhuma anormalidade causaram nos nasciturnos. Já na categoria D, relacionam-se os medicamentos que têm causado um aumento na incidência de malformações fetais ou outros defeitos permanentes. As outras categorias (B1, $B 2$, B3 e C) relacionam fármacos cujos efeitos colaterias provocam danos de maior ou menor influência sobre os fetos.

Nada mais tendo a sugerir, parece-me que o trabalho elaborado pela Dra. Suely Rozenfeld é de grande valor técnico-científico e sua publicação será muito útil como documento para consulta e esclarecimento na área da farmacovigilância.
Jorge Bermudez

Escola Nacional de Saúde Pública, Fundação Oswaldo Cruz, Rio de Janeiro, Brasil.
O artigo de Suely Rozenfeld vem preencher um vazio e propor uma discussão das mais atuais, instigantes e oportunas no que se refere às questões que permeiam a política de medicamentos e assistência farmacêutica. Evidentemente que não esperaríamos coisa diferente. Inicialmente, contextualiza com clareza e destaca a necessidade de que o Brasil mude o perfil policial e cartorial que ao longo dos anos vem caracterizando as ações de vigilância sanitária. Incorporando instituições acadêmicas, é possível estabelecer um sistema ágil de notificação e monitoramento capaz de mudar radicalmente o uso de medicamentos em nosso país.

No Brasil, o arcabouço legal existe e é extenso. Compreendendo decretos-leis, decretos, leis, portarias e outros instrumentos legais, a legislação pode ser considerada das mais avançadas do País, e aquela relativa especificamente a medicamentos, como levantado e discutido por Moreira Lima et al. (1994), se corretamente implementada, elevaria o Brasil ao patamar central no que se refere à fundamentação legal. Entretanto, além da preocupação com o processo de harmonização atualmente em curso nos países que compõem o Mercado Comum do Cone Sul (Mercosul), é fato notório o desrespeito à legislação em nosso país. Exemplo recente é o Decreto 793/93, que estabelece a obrigatoriedade de utilizar a denominação genérica dos medicamentos destacados em relação aos nomes de marcas, o que não é implementado nem cumprido, quer pela indústria, quer pelo Ministério da Saúde (Bermudez, 1994; 1995; Bermudez \& Possas, 1995).

No âmbi to desta lógica, a Portaria SVS 40, de 9/5/95, estabelece a criação de uma comissão para propor a implantação de um sistema nacional de farmacovigilância, como menciona Suely Rozenfeld. Passados dois anos, é de se perguntar se a proposta ficou no papel ou se alguma ação nesse sentido já foi implementada. Quantas vezes a dita comissão já se reuniu, se é que efetivamente ela foi estruturada, e quem são seus integrantes e suas respectivas representatividades?

Ao levantar em seu artigo a questão da Farmacologia Clínica, consideramos que este é um dos eixos mais importante e que podem vir a possibilitar uma mudança radical nos padrões de prescrição, dispensação e consumo de medicamentos. Constatamos o quanto o Brasil se encontra defasado, uma vez que a Organização Mundial da Saúde já vem propondo uma abordagem como esta há quase três décadas, ao passo que apenas hoje esta começa a se 
incorporar à agenda da saúde no Brasil (WHO, 1970).

Esta constatação nos remete ao ensino da Farmacologia no Brasil. Esse ensino é arcaico e tradicional na maioria das escolas médicas nos grandes centros. I niciativas modernas são escassas e restritas a determinadas instituições que contam com profissionais de vanguarda. Destacamos aqui o Rio Grande do Sul (Fuchs \& Wannmacher, 1989, 1992, 1996, 1998).

Consideramos também que, no Brasil, merecem destaque as atividades que determinados setores do Ministério da Saú de vêm implantando, por se tratar de assuntos que inevitavelmente irão interagir com o conjunto de ações relacionadas com a famacovigilância. Especificamente, destacamos o processo de revisão da Relação Nacional de Medicamentos Essenciais(Rename) e a formulação, discussão e posterior implantação e avaliação da Política Nacional de Medicamentos.

Os marcos históricos que a autora levanta, principalmente estabelecendo a relação com as reações adversas dos medicamentos, trazem-nos à reflexão a distância entre as etapas que marcaram a evolução da agência reguladora dos Estados Unidos da América (Food and Drug Administration) e a nossa regulação sanitária.

Cabe um comentário aos denominados 'tempos modernos', que têm seu início no mundo a partir do desastre da talidomida, o que deu origem a uma série de ações em diversos países. Enquanto isso, o Brasil efetivamente consolidou um sistema cartorial para lidar com as questões referentes ao registro e fiscalização de medicamentos e outros produtos para consumo humano. Hoje, esse sistema, já deficiente na sua formação, sofre as tentativas de desregulamentação decorrentes do processo de homonização em curso nos países que compõem o Mercado Comum do Cone Sul, ou Mercosul.

Tempos modernos, então, para o Brasil, incluem uma segunda geração de malformações provocados pelo uso da talidomida, conforme tivemos a oportunidade de discutir recentemente (Oliveira et al ., 1997). Tempos modernos, no âmbito da vigilância sanitária no Brasil, são as tentativas frustradas de retirar os hepatoprotetores, as associações de antibióticos em dose fixa e enfrentar a resistência descomunal da indústria, que alça o Brasil ao patamar de um dos cinco mai ores mercados de medicamentos do mundo, com um perfil que consideramos absolutamente irracional, baseado apenas na mercadização e venda de produtos não essenciais.
O artigo apresentado por Suely Rozenfeld, além de atual, instigante e oportuno, como mencionamos ao início desta discussão, representa um passeio pela História, associado a um texto rico e didático, com uma revisão extensa dos diversos aspectos relacionados com a farmacovigilância. A descrição da classificação das reações adversas é merecedora de elogio.

Concluímos nossa consi deração, chamando a atenção para a necessi dade de estabelecer uma ponte efetiva entre as ações de farmacovigilância e o uso racional de medicamentos, prática que vem merecendo cada vez mais atenção por parte das agências internacionais e dos países centrais (WHO, 1991, 1992, 1994, 1997; Dukes, 1993; Hogerzeil, 1995). Novos tempos e novas diretrizes também deverão ser implantados no Brasil. Sinceramente, esperamos que as reflexões contidas no artigo de Suely Rozenfeld e os comentários diversos possam induzir as instituições acadêmicas a se engajarem na luta árdua, permanente e sem tréguas, a fim de, efetivamente, podermos construir um modelo de atenção à saúde que resgate os conceitos de eqüidade, universalidade e resolutividade assegurados pela legislação e que ainda não conseguimos implementar. A farmacovigilância, a vigilância em saúde e a assistência farmacêutica são partes integrantes destas propostas. Sua construção depende de nossos esforços conjuntos.

BERMUDEZ, J. A. Z., 1994. Medicamentos genéricos: uma alternativa para o mercado brasileiro. Cadernos deSaúde Pública, 10:368-378.

BERM UDEZ, J. A. Z., 1995. Indústria Farmacêutica, Estado e Soci edade: Crítica da Política de Medicamentos no Brasil. São Paulo: Hucitec/ Sobravime.

BERMUDEZ, J. A. Z. \& POSSAS, C. A., 1995. Análisis crítico de la política de medicamentos en el Brasil. Boletin dela Oficina Sanitaria Panameriana, 119:270-277.

DUKES, M. N. G., 1993. Drug Utilization Studies. Methodsand Uses. Copenhagen: WHO. (WHO Regional Publications.) (European Series, 45)

FUCHS, F. D. \& WANNMACHER, L., 1989. Farmacologia Médica: Abordagem de Solução de Problemas. 4a ed., Porto Alegre: Editora da UFRGS.

FUCHS, F. D. \& WANNM ACHER, L., 1992. Farmacologia Clínica. Fundamentos da Terapêutica Racional. Rio de Janeiro: Guanabara Koogan.

FUCHS, F. D. \& WANNMACHER, L., 1996. Exercícios de Farmacologia Aplicada. Passo Fundo: Editora Universitária.

FUCHS, F. D. \& WANNM ACHER, L., 1998. Farmacologia Clínica, Fundamentos da Terapêutica Racional. 2a, ed., Rio de Janeiro: Guanabara Koogan.

HOGERZEIL, H., 1995. Promoting rational prescrito: an international perspective. British Journal of Clinical Pharmacology, 39:1-16.

MOREIRA LIMA, L. F.; MELLO, A. L.; GOMES, C.; PAZ, E. P. \& MOURA, M. L., 1994. Vigilância Sanitária 
de Medicamentos e Correlatos. Rio de Janeiro: Qualitymark.

OLIVEIRA, M. A.; BERMUDEZ, J. \& SOUZA, A. C. M., 1997. Talidomida no Brasil: o pesadelo da mutilação autorizada. V Congresso Brasileiro de Saúde Coletiva. Águas de Lindóia, SP, 25 a 29 de agosto de 1997. Livro de Resumos.

WHO (World Health Organization), 1970. Clinical Pharmacology. Scope, Organization, Training: Report of a WHO Study Group. Geneva: WHO. (Technical Report Series, 446)

WHO (World Health Organization), 1991. Clinical Pharmacology: The European Challenge. Copenhagen: WHO. (WHO Regional Publications.) (European Series, 39)

WHO (World Health Organization), 1994. Guide to Good Prescribing. A Practical Manual. Geneva: WHO.

WHO (World Health Organization), 1992. Operational Research on the Rational Use of Drugs. Geneva: WHO.

WHO (World Health Organization), 1997. The Use of Essential Drugs. Seventh Reporth of the WHO Expert Committee (including the revised Model List Essential Drugs). WHO Technical Report Series 867. Geneva: WHO.

\section{Maúrício Gomes Pereira}

Departamento de Saúde Coletiva, Faculdade de Ciências da Saúde Universidade de Brasília, Brasília, Brasil.
O artigo em tela, sobre farmacologia, mostra, com muita propriedade, o estado da arte sobre o assunto (Rozenfeld, 1998). Numerosos pontos nele contidos são dignos de nota, embora somente alguns poucos possam ser aqui comentados.

Em primeiro lugar, é sempre bom ter em mente que a terapêutica e a medicina, de maneira geral , não são matemática. Não são ciências exatas. $\mathrm{O}$ homem tem um complexo sistema regulador, profundamente influenciado pelo meio ambiente físico, biológico e social que o cerca. As reações do organismo aos medicamentos podem variar de pessoa a pessoa, embora, em termos populacionais, elas possam ser reconhecidas, desde que um acompanhamento adequado tenha sido feito. É aí que reside a grande dificuldade.

Os temas, em geral, só podem ser investigados parcialmente, e os homens de ciência sabem disso. A realidade é sempre muito complexa. Os investigadores, para pesquisar um dado assunto e na impossibilidade prática de analisá-lo em suas múltiplas relações e intera- ções, isolam uma situação para estudo e simplificam as condições de observação. Por meio de critérios de inclusão e exclusão de participantes, e de decisões quanto ao tamanho da amostra e do conteúdo dos instrumentos de coleta de dados, são afetados determinados grupos de pacientes e não são levados em consideração alguns indicadores ou efeitos, o que limita a generalização dos resultados da investigação e até mesmo a utilidade de sua conclusão. Isso é muito nítido nas pesquisas sobre medicamentos. Nelas, após os estudos laboratoriais bási cos e os preliminares, de natureza clínica, chega o momento de realização dos ensaios clínicos controlados, para determinar a eficácia e a segurança do produto (Pereira, 1995). Com os tamanhos usuais de amostra utilizados para determinar a eficácia de um produto, que se situam, no máximo, na casa de algumas poucas centenas de pessoas, muitas reações adversas não serão jamais detectadas nessa fase de investigação, seja porque elas se constituem em eventos da incidência rara (por exemplo, uma reação em cinqüenta mil usuários), seja porque só ocorrem após um longo período de tempo, quando a investigação já terminou e o seguimento dos participantes não está mais ocorrendo. Daí, as críticas que se fazem, com razão, aos ensaios clínicos controlados. Eles, quando bem realizados, dão resposta precisa somente a um número restrito de questões (Block, 1995). Mas, ao lado de suas limitações, os ensaios clínicos controlados têm aspectos positivos e um importante papel a desempenhar, evitando armadilhas dos estudos não controlados, sendo mesmo eventos que, considerados indispensáveis, em muitas situações, como elo final na cadeia de têm como resultado a liberação do produto para comercialização. Porém, isso ainda não é tudo.

Quando um produto é finalmente aprovado, e rotulado como eficaz e seguro para ser consumido pela população, começa uma outra fase, a da vigilância pós-comercialização. Para que esse processo atinja seus objetivos, tem-se que construir um banco de dados sobre a saúde dos usuários, incluindo as reações adversas por eles apresentadas. Todo banco de dados, por sua vez, é avaliado em termos, pelo menos, da cobertura populacional que alcança e da precisão das informações que contém. É difícil construir um banco de dados com essas características, em uma sociedade em transição, relativamente pobre, com as cidades inchadas e muito desemprego, na qual os recursos raramente existem para montar e fazer funcionar tal estrutura. Mas o esforço para instituir uma vigilância pós-comercialização, de alto nível, 
não deve ser descurado. E necessita sair do terreno apenas das intenções para a sua aplicação rigorosa. Precisamos de soluções criativas, práticas e apropriadas para as nossas condições; temos também de testá-las para verificar se realmente funcionam e divulgar amplamente os seus resultados. Esse é um grande desafio para a nossa intelectualidade, para os nossos profissionais de saúde. Um desafio que precisa ser aceito.

ROZENFELD, S., 1998. Farmacovigilância: elementos para a discussão e perspectivas. Cadernos de SaúdePública, 14:237-263.

PEREIRA, M. G., 1995. Epidemiologia: Teoria e Prática. Rio de Janeiro: Editora Guanabara-Koogan: 316.

BLOCK, G., 1995. Are clinical trials really the answer? American Journal of Clinical Nutrition, 62(Suppl.): 15.117S-15.120S.

\section{Gil Sevalho}

Departamento de Farmácia Social, Faculdade de Farmácia, Universidade Federal de Minas Gerais, Belo Horizonte, Brasil.
Como contribuição ao debate do artigo Farmacovigilância - elementos para a discussão eperspectivas, de Suely Rozenfeld, preten do abordar a questão conceitual da farmacovigilância numa perspectiva que a aproxima da vigilância epidemiológica, procurando assim estabelecer uma discussão sobre seus objeto e escopo.

As origens históricas da vigilância epidemiológica devem ser buscadas no nascimento da quarentena, durante a peste negra do sécuIo XIV, na Europa (Romero \& Troncoso, 1981). Foi uma prática de vigilância voltada para contatos e suspeitos portadores de doenças transmissíveis, a qual participou da empresa capitalista colonial ista que, nos países agrário-exportadores, operou o controle e a erradicação das doenças transmissíveis nas áreas produtoras de matéria-prima, sob a orientação do mundo industrializado, no início do século XX. Um empreendimento autoritário, coercitivo e punitivo alicerçado na ordem simbólica das representações belicista da guerra contra os micróbios, movido pela recém-fundada microbiologia.
Os anos 50 trouxeram, para Langmuir (1976: 13), uma nova versão de vigilância aplicada "à doença específica mais do queaos indivíduos". Uma prática centrada não mais em doentes e suspeitos, mas no comportamento da doença. Já com esta concepção, voltava-se para as doenças transmissíveis o modelo cuja implantação mundial foi discutida na 21a Assembléia Mundial de Saúde (OMS, 1968), embora esta vigilância tenha sido ampliada nas décadas de 60 e 70 para "as doenças não infecci osas inclui ndo leucemia, anomal i as congênitas, "reações aos medicamentos" (grifo meu), problemas nutricionais e uma ampla vari edade de riscos ambientais eocupacionais" (Langmuir, 1976:13).

A vigilância epidemiológica acompanhou o movimento da Epidemiologia que, atendendo ao chamado dos tempos, transformou seu objetivo. A Epidemiologia passou de um interesse exclusivo nas epidemias de doenças infecciosas para outro que incorporou as doenças não infecciosas, enquanto as novas doenças de massa características do envelhecimento populacional do século XX, e, posteriormente, a avaliação de serviços e tecnologias de saúde e os agravos resultantes das diversas formas de violências, já na perspectiva de uma epidemiologia dos fatores de risco. Como se a reboque da Epidemiologia, a vigilância epidemiológica assim também se movimentou.

A preocupação com os efeitos adversos dos medicamentos alopáticos modernos só se tornou alvo de uma atenção sistematizada depois da chamada invasão farmacêutica do pós-guerra dos anos 40 e do desenvolvimento das grandes indústrias transnacionais que a gerou. Foi a partir de então, segundo Tognoni \& Laporte (1989:47), que “formou-se um campo de pressão em torno dos medicamentos como ferramenta terapêutica, que tevesua origem na indústria farmacêutica" e que "afetou os responsáveis pela prescrição e os usuários, propiciando a colocação do setor farmacêuti co numa disjunção permanente en tre cobrir numa necessidadesanitária real eassegurar numa expansão constante do mercado".

Esta pressão deve ser vista no âmbito de um fenômeno amplo e complexo. O panorama de desenvolvimento do proj eto industrial farmacêutico transnacional é o de uma sociedade medicalizada, quando as necessidades de consumo são produzidas com a intervenção médica no cotidiano humano.

Na década de 60 alguns movimentos sociais certamente foram importantes para o surgimento de uma preocupação sistematizada em relação aos efeitos indesejáveis dos medicamentos. Nos países desenvolvidos, com o inte- 
resse crescente pela qualidade dos serviços de saúde prestados, enquanto bens de consumo envolvidos nas conquistas relacionadas aos direitos civis, e com as inquietações atuariais privadas e pú bli cas com os altos custos da assistência, a utilização de tecnologias médicas passou a representar objeto de avaliação.

Foi também nos anos 60 que se deu o nascimento, nos Estados Unidos, de um "movimento cultural" relacionado com a "ética aplicada", que trouxe em seu bojo a "éti ca dos negóci os", a "éti ca ambiental" e a "bi oética" (Mori, 1994:332). E a bioética é o saber que trata dos limites éticos impostos à prática médica diante das possibilidades de intervenção advindas da produção tecnológica desenvolvida e comercializada pelo complexo médico-industrial, pela indústria de equipamentos médicos e medicamentos.

Especificamente no que diz respeito à principal tecnologia empregada na área saúde - o medicamento, cuja prescrição passou a definir a consulta médica e substituiu até mesmo o diagnóstico no colóquio médico-paciente - foi, como percebe Suely em seu artigo, marcante a contribuição do trágico episódio da talidomida no processo que deve ter originado a farmacovigilância. A ocorrência de focomelia foi detectada em 1961 a partir da denúncia de um pediatra alemão que associou a doença ao consumo por gestantes do sedativo talidomida. Os primeiros casos da malformação relacionados ao consumo do referido medicamento foram relatados pelo médico Widekund Lenz por meio de carta a uma revista médica internacional, e, segundo Biriell \& Olsson (1989), durante muitos anos esta foi a forma mais comum de comunicar as reações adversas aos medicamentos.

Nos anos 60 surgiram trabal hos pioneiros sobre uma vigilância sistematizada das reações adversas aos medicamentos e do seu uso enquanto potencial fator de risco (Cluff et al., 1964; Seidl et al., 1966; Smith et al., 1966a, 1966b).

A vigi lância pós-comercialização de medicamentos é, na definição de Last (1989:187), no Dicionário de Epidemiologia dirigido pela International Epidemiological Association, o "procedimento posto em marcha depois da autorização do registro de um novo fármaco; desenhado para procurar informação sobre o uso real do fármaco para uma determinada indicação, assim como sobre a aparição de efeitos indesejáveis. Método para o estudo epi demiológico das reações adversas aos medi camentos".

Nos sistemas ou programas de farmacovigilância, os elementos metodológicos fundamentais são: “1) a fonte ou fontes de informa- ção sobre as reações adversas (entrada de dados), 2) o procedimento de análise desta informação e 3) a comuni cação dos resultados aos interessados" (OMS, 1972). Como em qualquer sistema de vigilância epidemiológica, deve-se combinar a sel eção de eventos para notificação, a definição das variáveis que serão trabaIhadas e a indefinição das fontes de informação. Na perspectiva dos programas ou sistemas de farmacovigilância, a seleção de eventos pode partir seja da consideração de possíveis reações adversas, tomadas de uma forma geral ou de acordo com uma relação de ocorrências estabeleci da previamente, seja da definição de alguns medicamentos, cujo uso será acompanhado. Assim, o próprio uso de medicamentos poderá ser acompan hado e estudado, e esta é uma questão central que quero apresentar neste debate.

Uma característica tecno-administrativa é marcante na vigilância epidemiológica e permite tão-somente sua inclusão no âmbito evidentemente mais amplo e complexo da epidemiologia, reconhecendo esta última como disciplina científica voltada para o estudo do adoecer das populações humanas. E assim, dentro do espaço disciplinar da epidemiologia, deve ser analogamente posicionada a farmacovigilância em relação à farmacoepidemiologia, que Last (1989:73) define como o "estudo da distri bui ção edos determi nantes dos acontecimentos relacionados com os fármacos nas populações e a apl i cação deste estudo a uma terapêutica farmacológica eficaz".

Thacker \& Berkelman (1988) propuseram recentemente a expressão Vigilância em Saúde Pública (Public Health Surveillance), aceitando sob esta nova denominação uma definição adequada também à vigilância epidemiológi ca, ou seja, “a col eta, análi see interpretação sistemáticas e permanentes de dados sobre saúde pública, integradas à pronta disseminação dos dados a todos aqueles que devem conhecê-los". Em colaboração com outros autores, Thacker $\&$ Berkelman (Klaucke et al., 1988:1) falam no "processo de descrição e acompanhamento de um evento sanitário." (grifo meu). Para Thacker \& Berkelman (1988) a palavra contínua ou permanente (ongoing) resume um atributo crítico para a caracterização das ações de vigilância em saúde pública. Além disso, deve ser considerado ainda o aspecto da sistematização das ações. São estas características principais que identificam e fundamentam um sistema de vigilância como um sistema de informação para ação que tem por objetivo principal acompanhar eventos definidos e, se necessário, intervir oportunamente no seu curso. 
O conceito apresentado engloba evidentemente a farmacovigilância en quanto um sistema de informação-ação para detecção e controle das reações adversas aos medicamentos. Neste caso, em uma perspectiva mais ampla, a definição de evento sanitário poderia não envolver somente as reações adversas propriamente ditas, mas também outros eventos ligados à utilização de medicamento, definida pela OMS (1977) como “a comercialização, distribuição, prescrição e uso de medicamentos em uma sociedade, com ênfase especial sobre as conseqüências médi cas, sociais eeconômicas re sultantes". Colocado o requisito da prescrição como parte integrante do concei to de reação adversa, o uso de medicamentos revela-se um objeto mais amplo da farmacovigilância.

BIRIELL, C. \& OLSSON, S., 1989. O programa de farmacovigilância da OMS. In: Epidemiologia do medicamento - princípios gerais (J. R. Laporte, G. Tognoni \& S. Rozenfeld, orgs.), pp. 153-176, São Paulo: Hucitec/Rio de Janeiro: Abrasco.

CLUFF, L. E.; THORNTON, G. F. \& SEIDL, L. G., 1964. Studies on the epidemiology of adverse drug reactions - I. methods of surveillance. Journal of American Medical Association, 188: 144-151.

KLAUCKE, D. N.; BUEHLER, J. W.; THACKER, S. B.; PARRISH, R. G. \&TROWBRIDGE, F. L., 1988. Diretrizes para a avaliação de sistemas de vigilância. MMWR, 37: 1-22.

LANGMUIR, A. D., 1976. William Farr: founder of modern concepts of surveillance. International Journal of Epidemiology, 5: 13-18.

LAST, J. M., 1989. Dicionário de Epidemiologia. Barcelona: Salvat Editores.

MORI, M., 1994. A bioética: sua natureza e história. Humanidades, 4: 332-341.

OMS, 1968. La vigilancia de las enfermedades transmisibles. Cronica dela OMS, 22: 483-489.

OM S, 1972. Vigilancia farmacologica internacional: función de los centros nacionales. Serie de Informes Tecnicos, 498. (Genebra:OMS).

OMS, 1977. La selección de medicamentos esenciales. Serie de Informes Tecnicos, 615. (Genebra: OMS).

ROMERO, A. \&TRONCOSO, M. del C., 1981. La vigiIancia epidemiologica: significado e implicaciones en la pratica y en la docencia. Cuadernos $\mathrm{Me}$ dico Sociales, julho:17-28.

SEIDL, L. G.; THORNTON, G. F.; SMITH, J. W. \& CLUFF, L. E., 1966. Studies on the epidemiology of adverse drug reactions - III. reactions in patients on a general medical service. Bulletin of the Johns Hopkins Hospital, 119: 299-315.

SMITH, J. W.; JOHNSON, J. E. \& CLUFF, L. E., 1966a. Studies on the epidemiology of adverse drug reactions - II. an evaluation of penicillin allergy. The New England Journal of Medicine, 274: 9981002.

SMITH, J. W.; SEIDL, L. G. \& CLUFF, L. E., 1966b. Studies on the epidemiology of adverse drug reactions - V. clinical factors influencing susceptibility. Annals of Internal Medicine, 65 (4): 629-640.

THACKER, S. B. \& BERKELMAN, R. L., 1988. Public health surveillance in the United States. Epidemiol ogic Reviews, 10: 165-190.

TOGNONI, G. \& LAPORTE, J. R., 1989. Estudos de utilização de medicamentos e de farmacovigilância. In: Epidemiologia do Medicamento - Princípios Gerais (J. R. Laporte, G. Tognoni \& S. Rozenfeld, orgs.), pp.43-56, São Paulo: Hucitec/Rio de Janeiro: Abrasco.

\section{Eduardo Navarro Stotz}

Escola Nacional de Saúde Pública, Fundação Oswaldo Cruz, Rio de Janeiro, Brasil.
O trabalho apresentado por Suely Rozenfeld propõe uma discussão que considere a revisão conceptual e histórica do elemento central da farmacovigilância - as reações adversas causadas por medicamentos em seres humanos. A oportunidade de ampliar o debate para além dos aspectos estritamente técnicos do artigo consiste, a meu ver, na consideração da farmacovigilância enquanto parte de política regulatória na área da saúde, a ser ainda implantada no Brasil. O assunto abordado é extremamente relevante e atual: a política de saúde em nosso país, crescentemente 'inampizada', reduz-se cada vez mais à assistência médica na qual a principal tecnologia utilizada é o medicamento. Infelizmente, apesar do aumento dos gastos com assistência médica, a maioria da população continua vivendo uma situação de saúde grave e difícil.

A vigilância de medicamentos consiste em ações de caráter técnico-científico. Melhor dizendo, trata-se de ações fundamentadas e legitimadas cientificamente. À "cientificação da técnica" (Lenk, 1990) que se observa nessas ações, não corresponde, contudo, como a própria autora reconhece, um protocolo de diagnóstico (e, portanto, uma tecnificação da ciência experimental) suficientemente sólido e consensualmente aceito. Essa debilidade obriga-nos a lembrar a advertência de Steven Rose (Rose \& Appignanesi, 1989) de que, se a ciência pode ser vista como um espel ho da natureza, é um espelho curvo e distorcido pelas expectativas e visão de mundo daqueles que a dominam. $O$ fim de qualquer neutralidade possível é também o fim, nes ses tempos de ciência 'pós-normal' (Funtowicz \& Ravetz, 1997), de qualquer inocência. Nessa perspectiva, gostaria de chamar a atenção, em face dos problemas de natureza metodológica assinalados pela autora, para al gumas questões. 
Sistemas de monitoramento de reações adversas são cientificamente fundamentados em determinado tipo de racionalidade. A racionalidade médica dominante (alopática) no mundo ocidental segue o padrão de racionalidade da ciência moderna, fundada na visão analítico-reducionista e de caráter generalizante. Ainda que a idéia de multicausalidade seja proposta como modelo explicativo, na prática predomina a causalidade linear. Originada a partir da anatomoclínica, trata-se de uma medicina do corpo, das lesões e das doenças (Camargo J r., 1990). Mas há outras racionalidades médicas possíveis. A homeopatia, por exemplo, partindo do pressuposto da impossibilidade de conhecer todos os antecedentes causais das doenças, investiu, com Hahnemann, no conhecimento dos efeitos da doença em sua total idade - o que exigi tratar os doentes (ainda que conformados em 'tipos' de enfermos) e não a doença. Cabe ainda acrescentar que a investigação homeopática teve como ponto de partida o problema das reações adversas dos medicamentos, levando Samuel Hahnemann a abandonar a prática médica e iniciar os seus estudos sobre os medicamentos (Hahnemann, 1982).

Do ponto de vista social, por outro lado, a farmacovigilância está fortemente condicionada pelo processo de medicalização que caracteriza o desenvolvimento da medicina contemporânea. Um aspecto importante desse tema é o da iatrogenia farmacológica abordado por Barros (1995) e que remete ao problema das reações adversas - problema central da farmacovigilância segundo a autora.

Por último, fica a inquietação política relacionada tanto ao problema do protocolo de diagnóstico já comentado, quanto ao da carência de bases de informação/ notificação no Brasil. É sabido, ainda, ser a indústria farmacêutica fonte importante de informação dos prescritores (médicos, estudantes residentes, balconistas) de medicamentos. Tal situação apenas acentua a necessidade de pensar formas de regulação de caráter social. Uma política regulatória organizada através de um sistema nacional de farmacovigilância não deveria abranger também outros eventos ligados ao uso de medicamentos? Um sistema que possa considerar a complexidade dos fatores envolvidos na ocorrência das reações adversas (Sevalho, 1997), além de mais adequado do ponto de vista científico-técnico, não contemplaria melhor as exigências de uma forma de regulação socialmente controlada, na medida em que incluiria os diferentes atores relevantes na organização desse mesmo sistema?

BARROS, J. A. C., 1995. Propaganda deMedicamentos: Atentado à Saú de? São Paulo: Editora Hucitec/Sobravime.

CAM ARGO JR., K. R., 1990. (Ir)Racionalidade Médica: Paradoxos da Clínica. Dissertação de Mestrado, Rio de Janeiro: Instituto de Medicina Social, Universidade do Estado do Rio de Janeiro.

FUNTOWICZ, S. \& RAVETZ, J., 1997. Ciência pós-normal e comunidades ampliadas de pares face aos desafios ambientais. História, Ciências, Saúde: Manguinhos, 2: 219-231.

HAHNEMANN, S., 1982. Organon de la Medicina. Buenos Aires: Editorial Albatros.

LENK, H., 1990. Razão Pragmática: A Filosofia entre a Ciência e a Práxis. Rio de Janeiro: Tempo Brasileiro.

ROSE, S. \& APPI GNANESI, L., 1989. Para uma Nova Ciência. Lisboa: Gradiva.

SEVALHO, G., 1997. Vigilância Epidemi ológi ca e Farmacovigilância, "Gatos de um Mesmo Saco": Impressões Históri cas e Conceituais. (no prelo)

Helena Lutéscia L. Coêlho

Departamento de Farmácia, Universi dade Federal do Ceará, Fortaleza, Brasil.
O tema abordado pela Dra. Sueli Rozenfeld é da maior relevância e o conteúdo do artigo importante, tendo em vista, principalmente, as poucas publicações brasileiras existentes sobre o assunto. Agradeço, portanto, a oportunidade de contribuir nessa discussão.

O fato de um país estruturar o seu sistema nacional de farmacovigi lância e estar integrado ao Programa de Monitoramento de Reações Adversas a Medicamentos da OMS certamente não é suficiente para definir que o mesmo desenvolva uma política de medicamentos adequada, do ponto de vista da saúde pública. $\mathrm{Na}$ verdade, fazer parte desse clube de 45 países pode ser usado como álibi por governos no intuito de aparentar seriedade no trato da questão do medicamento, enquanto entregam a definição do mercado farmacêutico aos interesses mercantis. O oposto, no entanto, parece ser verdadeiro. Ou seja, o não possuir um sistema nacional de farmacovigilância ou equivalente reflete a pouca seriedade com que um país trata a questão do medicamento no bojo de suas políticas de saúde, ou, pelo menos, o seu des- 
preparo e inoperância para lidar com o assunto. Isto porque trata-se de uma atividade pouco custosa e de implementação gradativa, cujos desdobramentos potencializam sobremaneira a eficácia de uma política de medicamentos.

No caso do Brasil, é desconcertante e injustificável a inexistência de um programa ou sistema nacional de farmacovigilância, em que pesem as iniciativas feitas nesse sentido desde a década de 70. Para os técnicos brasileiros que comparecem a eventos internacionais na área, é sempre uma situação embaraçosa tentar explicar as razões por que isso acontece. Findamos sempre por recon hecer a nossa incompetência como agentes de influência na determinação das políticas de saúde dos nossos governos.

Exercitar a farmacovigilância no Brasil só tem sido possível no nível micro. Estudos isolados, iniciativas de monitorização de reações adversas também localizadas e sem grande repercussão. Valem o exercício e o aprendizado. A grande dificuldade quando se tenta ampliar o alcance desses estudos éa in existência de denominadores farmacoepidemiológicos, que são os índices de utilização de medicamentos (comercialização, distribuição, prescrição, dispensação e uso) necessários, juntamente com dados de morbi-mortalidade, para a avaliação dos riscos. Os organismos estatais vinculados à Vigilância Sanitária, Assistência Farmacêutica e Epidemiologia, os setores específicos do Ministério da Saúde, a indústria farmacêutica, não possuem de maneira estruturada, ou não disponibilizam ao público, dados nacionais relativos à utilização de medicamentos e causalidade epi demiológica. Perguntas tão essenciais, como: quantas são as especialidades farmacêuticas registradas no Brasil, quais estão no mercado, que grupos terapêuticos são mais consumidos e o perfil dos consumidores, quanto é distribuído pelo estado e o detalhamento das vendas no varejo etc., ficam sem resposta ou surgem na mídia oriundas de fontes não publicadas ou de difícil acesso.

Diante das dificuldades resultantes da indefinição oficial quanto a uma política de farmacovigilância no Brasil, ati vidades não convencionais assumem uma dimensão importante. Um exemplo disso tem sido a atuação da Sociedade Brasileira de Vigilância de Medicamentos (Sobravime), do Grupo de Prevenção ao Uso Indevido de Medicamentos (GPUIM), bem como ações do Instituto Brasileiro de Defesa do Consumidor (Idec) e do Conselho Federal de Farmácia.

Nesse sentido, pediria à Dra. Sueli Rozenfeld que comentasse sobre o caso Misoprostol,

um bom exemplo de como se pode fazer farmacovigilância de um modo criativo e eficaz, desde que se tenha a determinação e o compromisso de ir em busca da verdade e não de reter informações. É claro que esse modelo não substitui um serviço ou programa nacional de farmacovigilância, mas também é claro que não seria substituído por ele.

José Augusto Cabral de Barros

Departamento de Medicina Social Universidade Federal de Pernambuco, Recife, Brasil.
Ao longo do tempo, mas, especialmente nas décadas mais recentes de desenvolvimento da medicina e da indústria farmacêutica, o tratamento farmacológico foi assumindo destaque crescente no contexto dos serviços de saúde e na visão e prática dos seus usuários e dos profissionais que atuam no setor, sobretudo os prescritores. Uma conotação importante das conseqüências daí advindas é que o medicamento, ao inserir-se no bojo da sociedade moderna de consumo e ao não ficar infenso à ideologia que tudo submete à lógica de mercado, foi transformado em mercadoria como outra qualquer. Essa ideologia do consumo, reforçada sinergicamente, pela percepção da doença como explicável e, como coronário, determinando as alternativas de intervenção sobre ela tão-somente por meros processos de natureza biológica (visão mecanicista), conduz a um uso desmedido e irracional de medicamentos, o que vem, obviamente, a provocar um reforço dos seus efeitos maléficos. Inscrevem-se nestes últimos, entre outros fenômenos, as reações adversas. O texto objeto do presente comentário discorre mui apropriadamente sobre o tema, traçando sua evolução histórica, conceituação e estratégias adotadas para detectálas o mais precocemente possível, bem como para monitorizá-las.

De maneira muito superficial - como era esperável nos limites de propósitos do artigo é feita uma alusão aos estudos observacionais, certamente relevantes pela importância dos mesmos como contribuição ao trabalho da farmacovigilância. Estamos nos referindo aos chamados estudos PMS (Post-marketing SurveilIance Studies). A despeito dos limites justificáveis, cremos que poderiam ter sido sugeridas algumas referências bibliográficas que permitissem a eventuais leitores interessados am- 
pliar sua compreensão da importância do campo de atuação e resultados práticos da farmacovigilância, através dos estudos mencionados. Neste sentido, além dos textos mais adiante sugeridos e que de maneira mais genérica apontariam as diferentes abordagens que os supracitados estudos podem assumir, com as respectivas estratégias metodológicas, presumimos teria sido de interesse a citação de um ou outro exemplo prático de estudos específicos. No primeiro caso, creio enquadrarem-se os textos de Strom (1994) e de Hartzema et al. (1991); no segundo, como sugestão de um estudo transversal, apontamos o trabalho de Gillum et al. (1984); à guisa de sugestão de um estudo de utilização de medicamentos, para eventual leitura, apontaríamos o artigo de Anderson (1991); como trabal ho que segue o mé todo de caso-controle, sugeriríamos o realizado por Laporte (1991).

O objeto de atenção do artigo implicaria obviamente a ênfase, efetivamente outorgada de maneira, diga-se de passagem, bastante apropriada pela autora, ao método universalmente mais adotado para acompanhamento, registro e avaliação de reações adversas, representado pela notificação espontânea. Mesmo assim, reputamos ser uma lacuna a não referência ao método, implementado na Inglaterra, por iniciativa da Unidade de Vigilância e Investigação de Medicamentos da Universidade de Southampton que consiste no Prescription Events Monitoring (PEM). O objetivo principal do programa é detectar e quantificar de forma comparativa riscos que são demasiado pequenos para que sejam observados nos ensaios clínicos. Os critérios para que um fármaco seja incluído no programa são o interesse científico e a importância clínica do mesmo. Com base nos dados fornecidos pela Prescription Pricing Authority, identificam-se os pacientes que entrarão no estudo, bem como os médicos e as prescrições por estes realizadas. Remete-se, então, um questionário (green form) a ser preenchido pelos prescritores. Os eventos de interesse são definidos como qualquer diagnóstico novo, motivos de consulta ou internação hospitalar, bem como a piora ou mel hora no quadro clínico de uma doença, a suspeita de reação adversa ou outras queixas do doente, relacionadas com o medicamento sob investigação (Inman, 1986). Ainda que com as limitações, presentes, aliás, em qualquer dos métodos adotados, este sistema pode fornecer dados de grande utilidade. Seja qual for o método empregado, o que se quer é firmar ou infirmar a hipótese de correlação causal entre um evento adverso e um fármaco suspeito. Auguramos, como a autora, que os desdobramentos práticos do Sistema Nacional de Farmacoepidemiologia, por demais lentos no que se refere à implementação de um Sistema Nacional de Farmacovigilância, quiçá aproveitando das experiências já em curso, ten do a notificação voluntária como substrato, venha a representar, o quanto antes, contribuição de peso na detecção e acompanhamento das reações adversas a medicamentos no País.

ANDERSON, F. A., 1991. Physician practices in the prevention of venous tromboembolism. Annals of Internal Medicine, 115:591-595.

GILLUM, R. F., 1984. Coronary heart disease mortality trends in M innesota, 1960-80: The Minnesota heart survey. American Journal of Public Health, 74:360-362.

HARTEZM A, A. G.; PORTA, M. S. \& TILSON, H. H., 1991. Pharmacoepidemiology - An Introducion. Cincinaty: Harvey Whitney Books.

INMAN, W. H. W.; RAWSON, N. S. B. \&WILTON, L. V., 1986. Prescription event-monitoring (ED) monitoring. In: Monitoring for drug safety MTP (W. H. W. Inman, ed.), Lancaster: Press Limited.

LAPORTE, J. R., 1991. Upper gastrointestinal bleeding in relation to previous use of analgesica and nonsteroidal anti-inflamatory drugs. Lancet, 337:8589.

STROM, B. L., 1994. Pharmacoepidemi ology. England: John Wiley and Sons. 
O autor responde

The author replies

Suely Rozenfeld

\section{Paulo Barragat}

Os comentári os do Prof. Barragat enriquecem este debate com a sua larga experiência no campo da produção farmoquímica e no Conselho Consultivo da CEME. Tenho estado atenta ao efeito danoso dos produtos ineficazes, e também dos produtos eficazes usados inadaquadamente, como é o caso da talidomida, cuja múltipla eficácia o professor aponta: sedativo, anti-emético e poderoso anti-inflamatório. Já na década de 1970, apresentei um caso de má-formação congênita dos membros suspeita de ter sido ocasionada pela talidomida (Rozenfeld, 1974); posteriormente, na elaboração de um guia terapêutico, fiz constar extensos quadros onde aparecem os fármacos que podem produzir más-formações congênitas, os que quando administrados às mães podem atingir o feto e o recém-nascido, bem como aqueles que são contra-indicados durante a lactação (Rozenfeld \& Pepe, 1992).

Atualmente, com a expansão do uso da talidomida para os indivíduos portadores de AIDS, a implantação de um sistema de monitoramento de reações adversas daria uma contribuição inestimável, funcionando como um verdadeiro observatório para registro de casos nacionais e para o desencadeamento de ações voltadas para a redução da prevalência dos mesmos.

\section{Jorge Bermudez}

Uma das decisões mais relevantes no campo da regulamentação dos medicamentos, tomada pelo Ministério da Saúde em 1993, com a participação do Prof. Bermudez, foi a edição do Decreto 793, que estabelece a obrigatoriedade de utilizar a denominação genérica em destaque, com relação aos nomes de marca. Creio mesmo que a sua importância - como a de muitas medidas legais no campo da regulamentação e da fiscalização - reside em grande parte nas mudanças culturais que podem provocar, independentemente do seu cumprimento pelos fabricantes. É interessante lembrar que, na década de 1980, o anúncio de que os sucos de frutas apresentavam teores de dióxido de enxofre acima do preconizado nas normas, fez praticamente desaparecer algumas indústrias produtoras. Infelizmente, os dados de consumo de medicamentos não são disponibilizados para a sociedade, mas é de se supor que algo semel hante ocorra. A discussão dos problemas e das alternativas relacionados aos medicamentos, a revisão crítica das relações individuais e coletivas que são estabelecidas com os fármacos, assim como o seu valor simbólico, são ações que podem contribuir tão poderosamente para a mudança de hábitos como as próprias mudanças nas bulas e nas embalagens.

Compartilho com o Professor Bermudez o otimismo quando à futura e breve construção de um modelo de atenção à saúde que possa resgatar os conceitos de eqüidade, universalidade e resolutividade que a legislação assegura. Compartilhamos, com diferenças de tonalidade, um certo pessimismo com relação às medidas tomadas após o desastre da talidomida no Brasil. Enquanto em vários países as legislações tornaram-se mais restritivas e os organismos internacionais investiram na difusão de políticas mais agressivas, no Brasil consolida-se um sistema de vigilância sanitária cartorial que, ademais, vem sofrendo nos últimos anos, algumas investidas rumo à desregulamentação. Entretanto, alguns trabalhos acadêmicos vêm dando conta de que essa área tem evoluído com movimentos nem sempre lineares, contraditórios e que, dependendo do período, podem pender para o lado da defesa ativa dos interesses dos consumidores (Souto, 1996; Costa, 1998).

\section{Maurício Gomes Pereira}

Embora um sistema de vigilância pós-comercialização necessite a construção de um banco de dados, como afirma o Prof. Pereira, penso que tal construção é parte integrante do próprio processo de criação do sistema, e não um pré-requisito para o funcionamento do mesmo. A grande variedade de métodos e técnicas de vigilância pós-comercialização disponíveis permite que se vá coletando informações, por exemplo, através de notificação espontânea de reações adversas, lado a lado com o desenvolvimento de estudos observacionais bem desenhados, ou ainda de estudos de util ização que empreguem informações geradas em unidades de atenção médico-sanitárias, em municípios, em regiões ou ainda em sistemas de atenção fechados, tais como os planos de saúde de grandes empresas. 
Combinar as várias estratégias possíveis não exige necessariamente grande quantidade de recursos financeiros, mas requer criatividade e persistência, inclusive, para ampliar os espaços institucionais disponíveis para tais práticas.

\section{Gil Sevalho}

Quando o Prof. Gil Sevalho traz para o debate as articulações entre a Vigilância Sanitária e a Vigilância Epidemiológica, ele está se colocando na crista de uma vaga al tamente inovadora em termos teóricos e no campo das práticas de saúde pública. Nela, encontram-se trabalhos acadêmicos recentes na linha das análises históricas de políticas públicas (Waldman, 1991; Costa, 1998) e também experiências ligadas à rede de serviços de saúde ancoradas na epidemiologia e no direito sanitário (OPS, 1994; SMS, 1992)

Com relação à limitação do campo da Farmacovigilância à detecção dos efeitos do uso dos fármacos, excluindo os chamados estudos de utilização, penso que mais do que uma questão de classificação, trata-se de um dilema conceitual. Abordei brevemente este aspecto num trabalho recente (Rozenfeld, 1997) onde sustento a posição de manter tal exclusão; isso porque entendo a farmacovigilância como campo da epidemiologia e portanto sujei to à sua (dela) própria definição: estudo da distribuição e dos determinantes dos agravos à saúde em populações humanas. Estudos de custos da assistência farmacêutica, análises antropológicas, estudos de prescrição e muitos outros estariam enquadrados como estudos de utilização. É desnecessário dizer que não há ordem hierárquica de importância entre ambos e que, na prática investigatória, eles costumam aparecer complementando-se.

\section{Eduardo Navarro Stotz}

A vertente abordada pelo Prof. Stotz agrega uma nova dimensão ao debate, tendo como foco a concepção do Sistema de Farmacovigilância como sendo de base farmacológica exclusiva, ancorado em associações bipolares e encerrado em órgãos administrativos. No entanto, as práticas atuais não sustentam essa visão; em primeiro lugar, porque o princípio que norteia as práticas investigatórias é o da multicausalidade e portanto variáveis ligadas aos indivíduos, sejam elas demográficas, relacionadas a comportamentos ou ainda ao estado de saúde devem ser consi deradas; além disso, o ambiente universitário on de se desenvolvem os cen- tros de farmacovigilância permitem não apenas o convívio com uma atitude crítica permanente, como também tornar o debate permeável a amplos segmentos sociais. A experiência do Conselho Federal de Farmácia na implantação de uma rede de centro de informações sobre medicamentos é relevante nesse sentido.

Está claro que esses centros atuam tendo como parâmetro a racionalidade médico-terapêutica alopática, ocidental e contemporânea e que há incontáveis caminhos para questioná-la.

Mas a tradição cultural de cada país, assim como as características dos grupos envolvidos determinarão o caráter mais ou menos abrangente a profundidade do conteúdo crítico dos centros de farmacovigi lância. Para ilustrar: o debate em torno das possíveis más-formações congênitas resultantes do uso do misoprostol, a partir dos estudos farmacoepidemiológicos desenvolvidos pelo GPUIM na Universidade Federal do Ceará, levou à reflexão sobre a hipocrisia de uma sociedade que ainda considera o aborto provocado como uma prática criminosa. A discussão sobre as valvulopatias resultantes do uso de anorexígenos pode colocar na pauta os conceitos socialmente construídos de beleza e de saúde, e o registro e verificação da associação entre o uso de Viagra e óbitos em homens pode acender o debate sobre a sexualidade masculina.

\section{Helena Lutéscia Luna Coelho}

Os estudos e as ações no campo da Farmacovigilância em nosso país, têm sido episódicos e localizados. Iniciativas de âmbito nacional e programas permanentes de ensino e pesquisa são raros. Entretanto, as condições para reverter este quadro estão dadas: a Portaria SVS no 40/ 95, objeto do texto em discussão, aliada a iniciativas concretas, tais como, a criação do GPUIM, que vem coletando reações adversas notificadas espontaneamente, são prova incontestável de que o panorama tende a mudar.

A grande dificuldade para ampliar o alcance desses estudos consiste, a meu ver, no escasso apoio político-institucional, bem como na cultura hegemônica, alimentada pela indústria farmacêutica, segundo a qual, o arsenal terapêutico disponível inexoravelmente está voltado para a cura, desconsiderando os aspectos econômicos que movem a produção do setor. Por esta razão, a ausência de dados sobre utilização é evidentemente um obstáculo, como assinala a Prof. Helena Lutéscia. No entanto, ele pode ser contornado através do uso de métodos que permitem aproximações, tais como 
a estratégia de casos e controle ou o estudo em populações delimitadas, nos quais seja possível estimar, com rigor, as prevalências de uso de medicamentos.

Quanto ao caso do misoprostol, conforme referido no texto, trata-se de um estudo que deve ser mencionado com destaque na produção científica do campo.

\section{José Augusto Cabral de Barros}

O texto apresentado para debate consiste numa revisão de al guns tópicos relevantes para a abordagem da Farmacovigilância, num contexto de análise conjuntural. Nesse sentido, procurei realçar aquilo que tem sido, na minha reflexão, a chave para permitir um salto na qualidade das políticas públicas do país, na área de medicamentos. Trata-se da implantação de um Sistema de Monitoramento de Reações Adversas, mergulhado num ambiente de difusão de informações sobre medicamentos para os profissionais e para os usuários. Sendo assim, apenas mencionei os estudos observacionais, sem descrever seus métodos e técnicas, disponíveis nos textos de epidemiologia, e citei alguns estudos realizados no Brasil (Fuchs et al., 1977; Koifman et al., 1987; Fonseca et al., 1991; Rozenfeld, 1997). Claro está que os sistemas de monitoramento funcionam basicamente como sistemas de alerta, mas não permitem quantificar os riscos, o que só pode ser feito com metodologia apropriada.

Por isso, agradeço os comentários do Prof. Cabral de Barros e reconheço a necessidade de mencionar, que ele apropriadamente assinala, no campo da Farmacovigilância, os estudos transversais de casos e controles e os de coortes, além de outros métodos próprios da área de medicamentos, tais como o Prescription Events Monitoring.

COSTA, E. A., 1998. Vigilância Sanitária - Defesa e Proteção da Saúde. Tese de Doutorado, São Paulo: Faculdade de Saúde Pública, Universidade de São Paulo.

OPS (Organização Pan-Americana da Saúde), 1994. Planejamento e Programação Local da Vigilância da Saú de no Distrito Sanitário. Brasília: OPS.

ROZENFELD, S., 1974. Apresentação de um caso recente de síndrome talidomídica em decorrência de sua utilização em pacientes com lepra. In: Anais do XX Congresso Nacional da Sociedade Brasileira de Genética. Recife.

ROZENFELD, S. \& PEPE, V. L. E., 1992. Guia Terapêutico Ambulatorial. Rio de Janeiro: Abrasco/Artes Médicas.

ROZENFELD, S., 1997. Reações Adversas aos M edicamentos em Mulheres da Tercei ra Idade - as Quedas como latrogenia Farmacoterapêutica. Tese de
Doutorado, Rio de Janeiro: Instituto de Medicina Social, Universidade Estadual do Rio de Janeiro.

SM S (Secretaria Municipal de Saúde), 1992. Vigilância à Saúde: a Experiência de Natal. Natal: SMS.

SOUTO, A. C., 1996. Saúde e Política. A Vigilância Sanitária no Brasil:1976-1994. Dissertação de Mestrado, Salvador: Instituto de Saúde Coletiva, Universidade Federal da Bahia.

WALDM AN, E. A., 1991. Vigilância Epi demiológi ca como Prática de Saúde Pública. Tese de Doutorado, São Paulo: Faculdade de Saúde Pública, Universidade de São Paulo. 